A Comparison of Memories of Fiction and Autobiographical Memories Brenda W. Yang ${ }^{1}$, Samantha A. Deffler ${ }^{2}$, and Elizabeth J. Marsh ${ }^{1}$

${ }^{1}$ Duke University

${ }^{2}$ York College of Pennsylvania

Author Note

Brenda W. Yang, Department of Psychology and Neuroscience, Center for Cognitive Neuroscience, Duke University. Data, Materials, and Supplemental Results available at osf.io/m2aew. Samantha A. Deffler, Department of Psychology, York College of Pennsylvania Elizabeth J. Marsh, Department of Psychology and Neuroscience, Duke University

This research was supported by the James S. McDonnell Foundation. We are grateful to David C. Rubin, Mark R. Leary, Felipe De Brigard, Hannah Moshontz, Matthew L. Stanley, and members of the Marsh and Imagination and Model Cognition Labs for helpful comments on earlier versions of this manuscript.

Correspondence concerning this article should be addressed to Brenda W. Yang, Department of Psychology \& Neuroscience, Duke University, Durham, NC 27708. E-mail: brenda.yang@alumni.duke.edu.

Word Count: 10,509 


\begin{abstract}
People consume, remember, and discuss not only memories of lived experiences, but also events from works of fiction, such as books, movies, and television shows. We argue that these memories of fiction represent an important category of event memory in their own right, best understood within an autobiographical memory framework. How do fictional events yield psychological realities even when they are known to be invented? We explored this question in three studies by comparing the memory content, phenomenological qualities, and functional roles of naturally occurring personal memories to memories of fiction. In Studies 1 and 2, we characterized the subjective experience of memories of fiction by adapting established measures of autobiographical remembering, such as the Autobiographical Memory Questionnaire (Rubin et al., 2003), Centrality of Event Scale (Berntsen \& Rubin, 2006), and items from the Thinking About Life Experiences scale (Bluck et al., 2005; Pillemer et al., 2015). In Study 3, we investigated similarities and differences in personal memories and memories of fiction for events from childhood or the recent past. In doing so, we observed the impact of a unique property of memories of fiction: their ability to be repeatedly re-experienced in their original form. Taken together, we argue that memories of fiction can be considered similar to other forms of autobiographical remembering and describe a theoretical framework for understanding memories of fiction in the context of other event memories.
\end{abstract}

Keywords: autobiographical memory, memories of fiction, episodic memory, event memory, functions of memory, narrative fiction 


\section{A Comparison of Memories of Fiction and Autobiographical Memories}

People are voracious consumers of fiction. We spend time and energy telling each other stories we know to be invented—reading novels, watching movies and television shows, listening to radio dramas, and more. Here, we focus on one enduring cognitive consequence of consuming fiction: people have memories of specific events from fictional sources, which may be remembered months or years later (Furman et al., 2007; Stanhope et al., 1993). How and why people remember, think, and talk about fictional events is a rich phenomenon — a "complex slab of human behavior" (Newell, 1973) — worthy of study in its own right. Understanding these memories of fiction also holds theoretical implications: a theory of memory is incomplete if it only allows for remembering veridical and directly experienced events, as our memory systems should also account for how and why people recollect and use memories of fiction.

To date, little research has examined the qualities of people's specific memories from fictional works consumed in everyday life, although stories are often the stimuli in cognitive experiments e.g., in studies relating to text processing, eyewitness report, event segmentation, and others. In contrast, much research has examined other aspects of people's engagement with narrative fiction. Given our focus on memory, reviewing this large body of work is beyond the present scope; instead, we summarize some of the overarching themes here. Researchers have studied how reading in general and literary fiction in particular contribute to the development of social intelligence (Black \& Barnes, 2015; Kidd \& Castano, 2013) as well as to people's knowledge about the world (Marsh et al., 2003; Potts et al., 1989; Potts \& Peterson, 1985). Consuming fiction can shift judgments about the world (Appel, 2008; Morgan \& Shanahan, 2010; Shanahan \& Morgan, 1999), persuading people and leading to changes in their behavior (Bandura, 2006; Green et al., 2003; Green \& Brock, 2000). Fictional works can be useful in 
applied settings, such as in "bibliotherapy" (Cuijpers, 1997), for rehabilitation (Billington, 2011), and in the classroom (Butler et al., 2009; Knippels et al., 2009; Marsh et al., 2012). Many of these research directions and applications assume that people remember fictional events, but relatively little is known about the memories of fictional events as consumed "in the wild."

\section{Past Research and Theoretical Perspective}

In this project, we explore the idea that memories of fictional events share important qualities with memories of one's personal past. The claim that memories of fiction and memories of lived experience are comparable may seem surprising at first, given that autobiographical memory is typically defined as memory for one's own past (Rubin et al., 1986). However, the idea is built on prior literature and has been implied by past scholars (Magliano et al., 2012; Rubin \& Umanath, 2015; Zwaan, 1999).

First, a large body of prior research supports a common form of representation between fictional events and ones experienced in the world. Readers of texts construct mental models (also called situation or event models; Johnson-Laird, 1983; Kintsch \& Van Dijk, 1978) that extend beyond lower level features of the text itself. Such models can include spatial layout, characters, temporality, causality, and intentionality (e.g., the event-indexing model; Zwaan et al., 1995). Mental models allow the reader to make inferences about actions and locations, an enormously adaptive cognitive feature (Raymond \& Zacks, 2017). Critically, the mental models derived from disparate formats, such as prose-based and visual media, are very similar. Models derived from text, auditory narratives, movies, pictures, or even video games (Gernsbacher et al., 1990; Magliano et al., 2001, 2014; Radvansky \& Copeland, 2006) exhibit similar properties. Such similarities led Gernsbacher to develop a structure-building framework that explicitly posits that comprehension of any information, regardless of modality, involves general cognitive 
processes (Gernsbacher et al., 1990; McDaniel et al., in press). This idea of a single system is parsimonious and fitting, given that this system almost certainly evolved prior to the development of written language (Boyd, 2009).

Second, recent research acknowledges that autobiographical memory is a broader category than traditionally circumscribed. Neuroimaging data (Schacter et al., 2015; Schacter \& Addis, 2007) has made clear that the same biological system that supports remembering the past also allows other types of simulations, including projections of the self into the future (Schacter $\&$ Addis, 2007) and memories of what might have been (De Brigard et al., 2016; Schacter et al., 2015). Such simulations draw on what is stored in memory but refashion the components to create something new. In other words, the system is flexible and constructive - a positive when planning for the future but a source of error when remembering the past (Schacter et al., 2011; Varga et al., 2019). Moreover, lived experience is not a prerequisite for a memory to be part of one's autobiographical record, a term we use to describe the facts and events that constitute our internal autobiography. People have memories of events that were never experienced (false memories; Loftus, 2005; Loftus \& Pickrell, 1995) as well as memories of events that feel real but are understood to not have occurred (non-believed memories; Otgaar, Scoboria, \& Mazzoni, 2014; Scoboria, Memon, Gawrylowicz, \& Clark, 2015). In other words, memories vary in the degree to which people believe the events within them occurred. Such belief is theoretically orthogonal to the objective reality of an event, as false memories are believed to have occurred. Belief is also distinct from the ability to vividly recollect or re-experience the event, as nonbelieved memories are relived, even while one does not believe the event to have occurred (Scoboria et al., 2014). 
In addition to belief, research also highlights another dimension: the agent in the memory. To wit, studies on vicarious and reported memories document how people recollect events that happened to other people or reported in mass media (Larsen, 1988; Larsen \& Plunkett, 1987; Pillemer et al., 2015; Thomsen \& Pillemer, 2017). In other words, people can have episodic-like remembrances where the self is not a direct agent, including anecdotes related by others. For example, one of the authors holds a vivid event memory of her partner on a plane when it was in the process of being (safely) diverted mid-flight due to mechanical failure; this detailed, vicarious memory includes vivid visual elements (e.g., oxygen masks dropping) and emotional components.

In other words, memories can vary both in belief in event occurrence and self as agent, yielding the two-dimensional representation shown in Figure 1; while the figure highlights two dimensions, it is not meant to imply that event memories only differ in these ways (Rubin, 2021a). The categories of memory we discuss above populate three of four quadrants in this twodimensional space. While these dimensions are likely continuous in nature, they are shown and discussed here as dichotomous for conceptual ease. Memories of events in narrative fiction can populate the remaining, bottom left quadrant: they represent memories of events known not to have occurred in the world and where the rememberer is also not the agent of the event. The present work examines whether there is empirical justification for including memories of fiction in the family of event memories that form part of our autobiographical record.

\section{Figure 1.}

Delineating Memories of Fiction: Two Selected Dimensions of Event Memories 


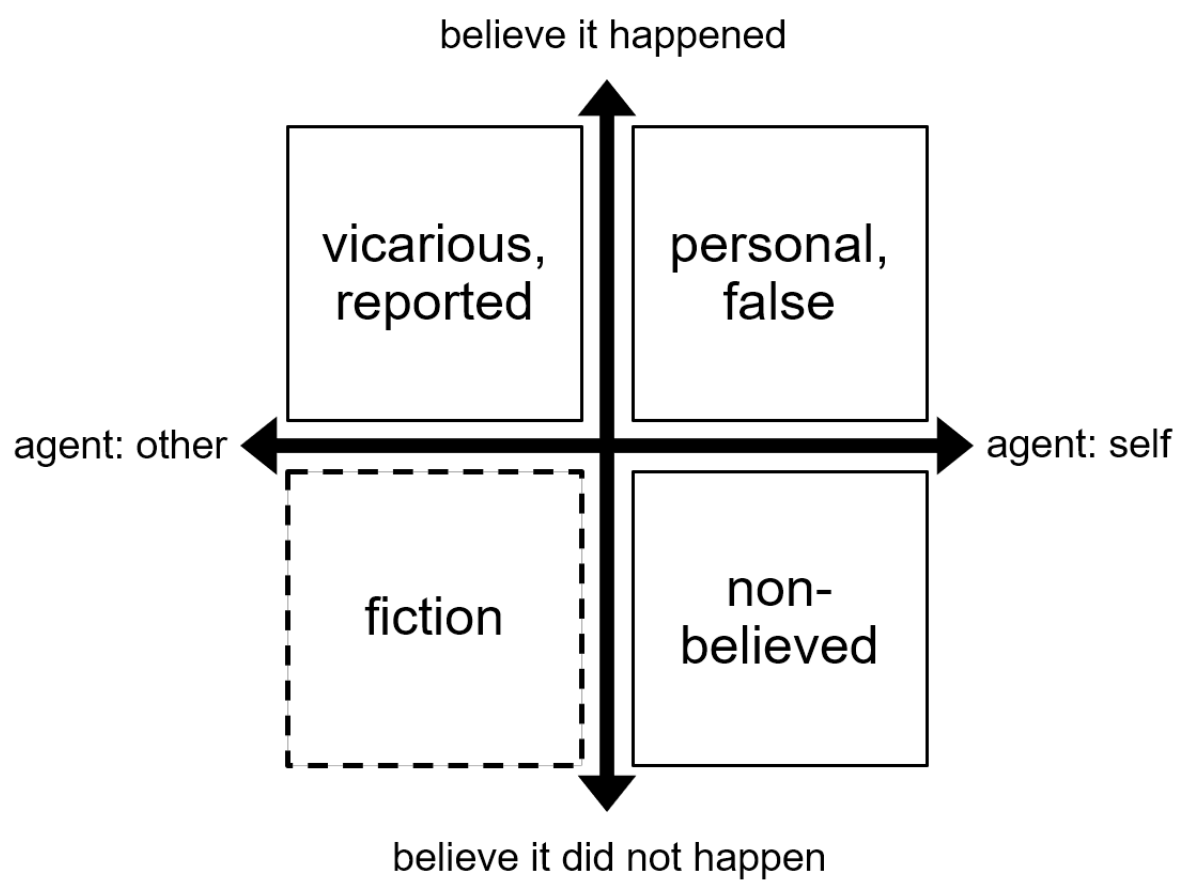

We note that the present research questions are distinct from previous work concerned with reality-monitoring i.e., discerning the difference between real and imagined events (Johnson, 1988; Kensinger \& Schacter, 2006). While errors in source-monitoring with respect to works of fiction certainly do occur, our aim is to characterize perhaps an even more basic phenomenon: understanding people's memories of events from works of fiction which are correctly identified as such. Popular fictional worlds form parts of the psychological landscape even while it is virtually impossible to mistake them for reality. Our work contributes to a different but equally important question: how do fictional events yield psychological realities even when they are known to be fictional?

\section{The Present Research}

Memories of fiction have not been examined systematically using the methodologies and measures developed to study autobiographical memories. Here, we adapt and extend tools from decades of scholarship on autobiographical remembering to the task of characterizing memories 
of fiction. In three studies, we empirically examine the idea that memories of fiction are event memories (Rubin \& Umanath, 2015) that can be considered part of the autobiographical record and thus are comparable to memories of lived experience.

In doing so, we used a broad definition of fiction, allowing participants to draw naturalistically on events from movies, television, novels, comic books, and other media. This choice was intentional and based on the large literature that suggests comprehension does not depend upon the surface properties of a text, auditory input, or visual stimulus: regardless of the form a given story takes, consumers extract abstract mental models that capture the structure of the story. Of course, memories of fiction may vary in interesting ways as a function of - for example - modality or literary quality, in the same way that memories of lived experience vary in uniqueness, emotionality, and importance (Gordon et al., 2009). To preview, the General Discussion references some exploratory analyses on this point. However, we choose to broadly sample fictional events given that we are at a starting point in understanding them, closer to where the field of autobiographical memory was in the 1970s. Our work sets the foundation for more nuanced questions about memories of fiction by extending methods for eliciting autobiographical memories to fictional ones, allowing us to capture information about the contents, qualities, and role of memories of fiction.

To the extent that memories of fiction are similar to event memories, people should be able to retrieve, describe, and rate them on various features. Our focus is on the phenomenology, which has long been a defining characteristic of autobiographical memories, especially as contrasted to knowledge (Tulving, 1985). When recalling the personal past, one often feels a sense of reliving the past or of traveling back in time (Baddeley, 1992; Tulving, 1983; 2002), vivid recall of details through mental imagery (Brewer, 1986; Rubin, 2006; Rubin, Schrauf, \& 
Greenberg, 2003), and belief in the veracity of the recollection (Brewer, 1996; De Brigard, 2017; Johnson et al., 1988). Here, we consider how fictional narratives may also exhibit similar properties, using questions typically used to probe the phenomenology of personal memories. For example, consider a participant who remembers the scene in George Lucas's seminal 1980 film The Empire Strikes Back in which a pilot (Han Solo) slices open the warm carcass of a large furry lizard (a tauntaun) and stuffs the film's protagonist (Luke Skywalker) into the animal, preventing Skywalker's frosty death on the ice planet Hoth. We use questions from the Autobiographical Memory Questionnaire (Rubin et al., 2003) to understand the memory's phenomenological qualities, such as its vividness, emotional valence and intensity, and a reexperiencing of the scene (a sense of reliving, recollection, or autonoesis). We collect these phenomenology measures in three studies using classic methods for probing autobiographical memories: a prompt to retrieve frequently rehearsed events (Study 1), using concrete nouns as cues (Study 2), and retrieving events from specific time periods (the recent past or childhood; Study 3). In all studies, we directly compare memories of lived experience to fiction for specific items as well as examine the overall pattern of relationships among memory features.

Across studies, we also include two measures to explore the functional roles that memories of fiction might play. Past work has explored three theoretically-driven categories for functions of autobiographical memory: directive (planning and decision-making), self (relating to one's identity and the sense of a continuous self over time), and social (developing and maintaining relationships; Bluck, 2003; Pillemer, 2003). We query whether these functions apply to memories of fiction with the Thinking About Life Events (TALE) questionnaire, as well as the Centrality of Events scale, which indicates how important a memory is to the sense of self (Berntsen \& Rubin, 2006). Finally, across studies we collected some basic information about the 
memories retrieved: a measure of their specificity, age, and (for memories of fiction) source of the memory.

\section{Study 1: Frequently Retrieved Events}

In Study 1, participants were instructed to retrieve specific memories of events they had thought or talked about often, a cue previously used in autobiographical memory research (e.g., Rubin \& Schulkind, 1997). Participants rated event memories_-both personal and fictional—for feelings of reliving, visual and auditory imagery, and belief in their accuracy, among other qualities, using items from the Autobiographical Memory Questionnaire (Rubin et al., 2003), as well as event centrality and functional significance (Berntsen \& Rubin, 2006; Bluck et al., 2005).

\section{Methods}

\section{Participants}

We recruited 105 participants (43 women; $M_{\text {age }}=34.2$ years, $\left.S D_{\text {age }}=11.0\right)$ from the United States through Amazon Mechanical Turk (AMT). In this sample, $41.9 \%$ of participants reported having at least a bachelor's degree, and $88.6 \%$ of participants reported taking at least some college courses. Participant responses were examined individually for data quality; no participants were excluded from analysis.

\section{Materials}

Materials and instructions for this and subsequent studies are available online at osf.io/m2aew.

To examine our primary questions around phenomenology, we adapted items from the Autobiographical Memory Qualities (AMQ; Rubin et al., 2003) questionnaire. We asked participants to rate event memories on how often they thought or talked about the event (rehearsal), visual imagery, auditory imagery, a sense of re-experiencing (reliving), belief in the 
accuracy of the event, strength of the emotions, positive valence, negative valence, intensity of emotions, and the visual perspective of the event (field or first-person, observer or third-person, and ability to switch between the two perspectives). All items were rated on 7-point scales with anchors throughout the scale. To ask about memories of fiction, we adapted the items as needed to refer to works of fiction. For example, we adapted the rehearsal item "Since it happened, I have thought or talked about this event" to "Since reading or seeing this event the first time, I have thought or talked about this event" in the fiction condition.

We also asked participants to report on the functional significance and centrality of events. We used Pillemer et al.'s adaptations of previous scales to allow comparison to previously published work on vicarious memories (2015). Thus, we used a 4-item version of the Centrality of Event Scale (CES; Berntsen \& Rubin, 2006) and a 5-item version of the Thinking About Life Events (TALE) questionnaire (Bluck et al., 2005; Bluck \& Alea, 2011). CES items were related to the event's impact on identity ("I feel that this event has become part of my identity"), status as a reference point (“This event has become a reference point for the way I understand myself and the world"), status in one's life story ("I feel that this event has become a central part of my life story"), and influence on other experiences ("This event has colored the way I think and feel about other experiences"). TALE items were related to the directive function (e.g., "My memory of this event impacts my life decisions"), social function ("My memory of this event influences the relationships I have with others"), and self function ("My memory of this event helps me to better understand myself'). Items were rated on a 5-point scale ( 1 = totally disagree, 5 = totally agree). Prior to collecting these data, we conducted a pilot study administering the full TALE questionnaire for both personal memories and memories of fiction; 
the conclusions drawn in the pilot are similar to those we report here, and so for brevity, we report the pilot for interested readers in Supplemental Results (osf.io/m2aew).

\section{Procedure}

After giving informed consent, we asked each participant to retrieve two memories of specific events they had talked or thought about often. Each participant provided one personal memory and one memory of fiction. We chose this approach in part because of little empirical precedent for cueing specific events from works of fiction: we reasoned that asking about wellrehearsed memories would maximize the chances participants would succeed at this task. We also chose only one event per condition to minimize the length of the task for online participants, increasing the chances of collecting high-quality responses.

Participants were given detailed instructions about what type of events they should be retrieving. For personal memories, they were told that events should be from their own life, ones they have thought or talked about often, and specific: "For example, do not write, 'eating breakfast' but try to think of a specific scene like, 'I was eating breakfast with my boss and I spilled maple syrup into her lap."” Instructions for memories of fiction were similar: participants were told that events should be from a work of fiction, such as a movie, book, or TV show, and not a real event, be one that they have thought or talked about often, and specific: "For example, do not write "Sherlock Holmes solves crimes" but try to think of a particular event or scene." For both conditions, they were told the events could be chosen from any time period in their life and that it was normal to spend a little time retrieving the event.

Immediately following retrieval of a memory, participants generated a short label (for personal memories) or named the work of fiction (for memories of fiction). They also gave a description of each event before estimating how long ago the event occurred and their age at the 
time of occurrence. For the fiction condition, participants also noted whether the event they generated was from a book or novel, movie, TV show, or another medium. After all memories were generated, participants were reminded of their previous descriptions and rated the qualities of each memory on AMQ, CES, and TALE items. Finally, participants provided demographic information and optionally provided explicit consent for their responses to be shared in academic settings (e.g., in talks and publications). If participants did not give explicit consent for their individual text responses to be shared in academic publications, their responses were redacted from the data available on OSF (osf.io/m2aew).

\section{Statistical Analyses (Studies 1 - 3)}

Analyses for Study 1 and all subsequent studies were completed in RStudio (2018). The alpha level was set to .05 for all analyses unless reported otherwise. Bonferroni corrections for multiple comparisons were implemented per family of analyses, when appropriate. Effect sizes were calculated using the 'effsize` package (Torchiano, 2020). Generalized linear mixed-effects models were run using the `lme4` software package (Bates, Maechler, Bolker, \& Walker, 2015). Significance for fixed effects was assessed using Satterthwaite approximations to degrees of freedom with the package `lmerTest` (Kuznetsova, Brockhoff, \& Christensen, 2017). Nine-five percent confidence intervals (CIs) were computed using parametric bootstrapping (number of simulations $=1,000)$. We computed mixed effects ANOVAs using the 'lme4' and 'lmerTest' packages in R, using a type III analysis of variance table and computing p-values with Satterthwaite approximations for denominator degrees of freedom (Bates et al., 2015, p. 4; Kuznetsova et al., 2017). Plots were created in RStudio using the 'ggplot`and 'fmsb ' packages (Nakazawa, 2019; Wickham, 2016).

\section{Results and Discussion}




\section{Memory Content}

\section{Specificity of Events}

All participants (100\%) were able to retrieve and describe specific event memories from fiction as well as their own lives. Table 1 provides examples of participants' responses from Study 1 and Study 2.

Table 1.

Sample Participant Responses in Studies 1 and 2

\begin{tabular}{|c|c|c|}
\hline & Memory of Lived Experience & Memory of Fiction \\
\hline Study 1 & $\begin{array}{l}\text { On October } 28,2008 \text { my daughter } \\
\text { was born. She was overdue, and her } \\
\text { mom was going to be induced that } \\
\text { day, but when we got to the hospital } \\
\text { the Dr. noticed that the baby's } \\
\text { heartbeat had dropped very low. It } \\
\text { ended up being that she had wrapped } \\
\text { her umbilical cord around her own } \\
\text { neck. Her mom had to have an } \\
\text { emergency C-section. In the end I } \\
\text { had a perfectly healthy daughter. It } \\
\text { was the most terrifying and happy } \\
\text { day of my life. }\end{array}$ & $\begin{array}{l}\text { On Scandal, I remember when Olivia } \\
\text { was at her dad's house trying to take } \\
\text { Jake away from him. I remember the } \\
\text { intensity of the scene as her dad held } \\
\text { the gun to Jake's head. Then her dad } \\
\text { let him go and they both left the } \\
\text { house scared. However, in the end, } \\
\text { her dad got what he wanted. }\end{array}$ \\
\hline Study 2 & $\begin{array}{l}\text { My junior year of high school, my } \\
\text { family decided to renovate our house, } \\
\text { so we had to move to a house fifteen } \\
\text { minutes away. The night before we } \\
\text { moved back home, I stayed up until } 2 \\
\text { AM packing up my room. It was the } \\
\text { latest I had ever stayed up in high } \\
\text { school. }\end{array}$ & $\begin{array}{l}\text { I am thinking of the scene from The } \\
\text { Office in which Pam gives birth to } \\
\text { hers and Jim's first child CC. Jim is } \\
\text { called into the delivery room as Pam } \\
\text { begins to "push" while Michael is } \\
\text { stuck outside because only family } \\
\text { members are allowed in the room. He } \\
\text { lights up a cigar when it is announced } \\
\text { CC is born but is quickly told to } \\
\text { extinguish it by a passing hospital } \\
\text { worker. }\end{array}$ \\
\hline
\end{tabular}

Note. Participant responses were minimally edited for grammar, spelling, and readability. 
We then confirmed that the events provided were specific. It would be possible, for example, for participants to provide memories of fiction, but for the events to be predominantly general in nature: for example, "Jim played many pranks on Dwight in The Office," rather than “Jim encased Dwight's stapler in yellow Jell-O, which Dwight pulls out of a drawer." A lack of specificity would have implications for understanding the phenomenology of the memories solicited (e.g., differences might suggest that memories of fiction are more semanticized than memories of lived experience). We used a coding scheme from previously published research (Pillemer et al., 1986), which coded memories as specific (containing an explicit description of a 'one-moment-time' event) or general (often going beyond a single event and presenting a theme for numerous, often recurring events). The first author and a trained research assistant coded the descriptions as specific, general, or mixed (clearly containing elements of both specific and general events). Agreement between coders was high: $87.2 \%$ overall.

We found that the majority of events elicited were specific $(90.8 \%)$, as requested in the instructions given to participants. Most disagreements were between events coded as "specific" by one rater and "mixed" by the other, and ratings were not significantly different between memory type conditions. Thus, we have fairly high confidence that that the events provided by participants in both conditions are specific in nature.

\section{Modality}

When retrieving memories from works of fiction, most participants described events from movies (52\%), with the remaining memories coming from books/novels (26\%), and television shows $(22 \%)$.

\section{Temporal Distribution}


On average, events described by participants occurred 11.0 years prior to the moment of retrieval $\left(M_{\text {personal }}=11.1 ; M_{\text {fiction }}=10.8\right)$. Figure 2 shows the temporal distribution of retrieved memories. Visual inspection of the temporal distributions of personal and fictional memories within each study reveals that they were quite similar.

\section{Figure 2.}

\section{Temporal Distribution of Event Memories in Study 1}

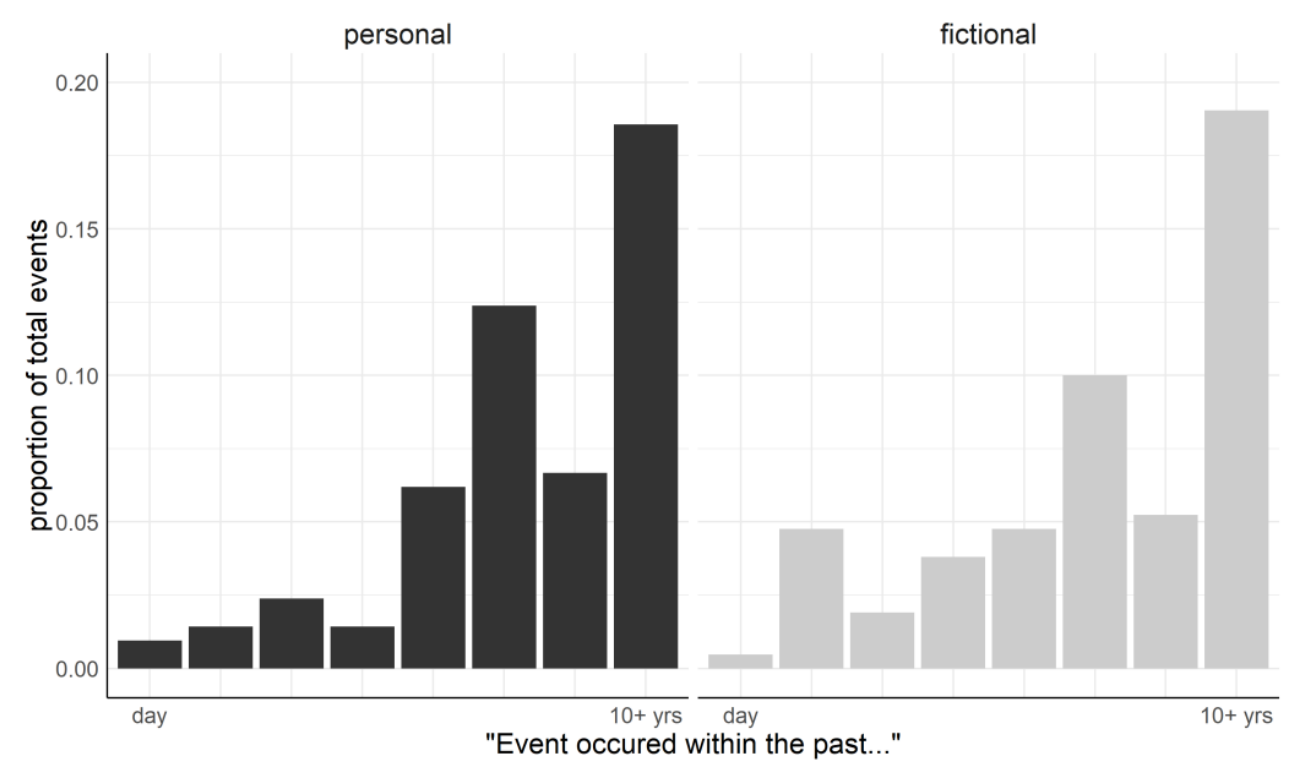

Note. Response categories from left to right: within the past day, within the past week, within the past month, within the past 3 months, within the past year, within the past 5 years, within the past 10 years, and more than 10 years ago.

\section{Memory Qualities}

Next, we examined our primary research question: how do phenomenological qualities of personal memories compare to those of memories of fiction? We compared potential differences between the two types of memories by computing $t$-tests for each AMQ item. Only reliving was 
statistically significant after correcting for multiple comparisons: $M_{\text {personal }}=5.11(S D=1.65)$, $M_{\text {fiction }}=3.50(S D=1.85), t(104)=8.55$, Cohen's $d[95 \% \mathrm{CI}]=0.83[0.55,1.12]$. One possible explanation for this stark difference in only the reliving measure is how we adapted this item to probe fictional events: "When remembering the event, I feel as though I am actually living it." No matter how vivid one's memory from a novel or movie may be, it is not likely to feel as though one is "actually living" through it for a number of reasons, including the plausibility of the fictional event. Thus, the construct of "reliving" for fictional events might also include something akin to, "When remembering the event, I feel as though I am re-experiencing it as I first read or saw it again." We include a new reliving measure to address this in Study 2.

Overall, people reported remembering many fictional events similarly to how they remember events from their personal lives: accompanied by a sense of reliving, often with vivid sensory imagery. Figure 3 illustrates these results in two ways. Panel A is a dot plot displaying means and standard errors, facilitating a comparison between personal and fiction conditions. Overall, we see that people consistently endorsed phenomenological experiences when recalling fictional events. Panel B is a radar plot, which depicts the relationship among individual items for personal and fiction conditions. In this radar plot, each spoke of the grid corresponds to an AMQ item, with mean ratings plotted moving outwards from the inside to the outside of the plot. Rather than examining comparisons between individual items, this view emphasizes the two resulting shapes. Here, we see that memories of lived experience and of fiction respectively, have a strong tendency to move together; indeed, these means are strongly correlated $(r=.83)$. This pattern is consistent with the claim that the differences between remembering memories of lived experiences and remembering fictional events are ones of degree, and that these memory 
types are expressions of the same underlying system for event memories (Rubin \& Umanath, 2015).

Figure 3.

Mean Ratings of Phenomenology for Study 1: (A) Dot Plot (B) Radar Plot

(A)
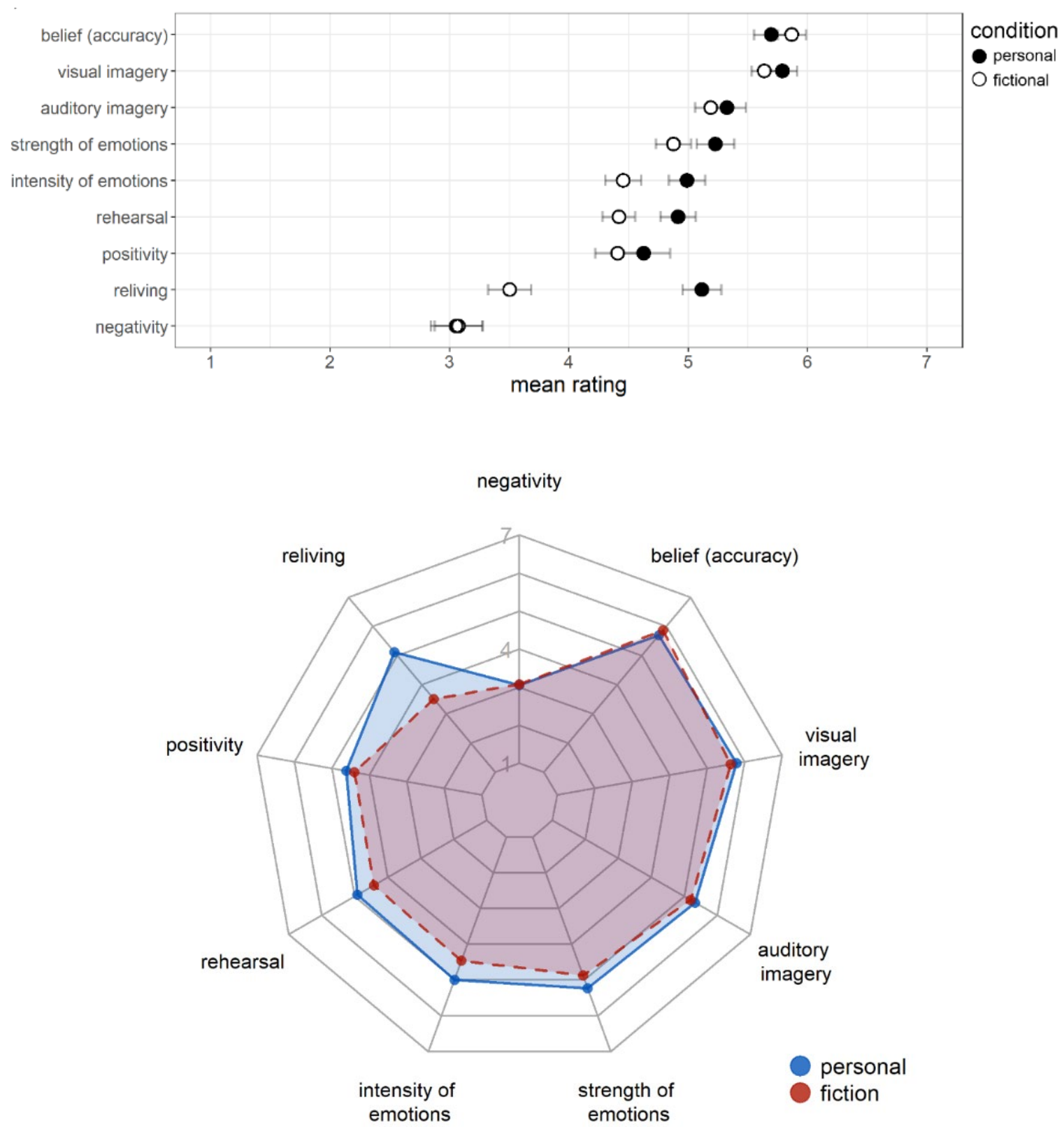

(B) 
Note. (A) Error bars represent standard error of the mean. Labeled endpoints of Likert scales indicated that "1" was a low value (e.g,. not at all) and "7" was high (e.g,. extremely). (B) Solid and blue lines represent means for personal memories; dotted and red lines represent means for memories of fiction.

\section{Visual Perspective}

We found that participants reported experiencing perspective in personal memories differently from memories of fiction: $\chi^{2}(3)=110.96, p<.0001$. Specifically, while most personal memories were remembered from the field perspective $(73.3 \%)$, memories of fiction were predominantly remembered from a third-person perspective (77.1\%). Most participants (53.3\%) reported being able to switch between perspectives for personal memories, while fewer participants $(41.0 \%)$ reported being able to switch for memories of fiction. However, it is possible that these differences were driven by how people originally experienced the event: whereas personal memories are all originally experienced from a field perspective, the perspective of fictional works varies, especially by the medium of the work. Because we are unable to tease apart these potential effects of modality, we refrain from interpreting these results further and report results for visual perspective in subsequent studies in Supplemental Results.

\section{Memory Role}

\section{Centrality of Events}

To compare the self-significance of events, we examined Centrality of Event Scale (CES) scores between personal memories and memories of fiction. The four items showed high reliability: Cronbach's $\alpha=0.93$ [0.92, 0.95]. We found that participants reported personal memories as more central to their self than memories of fiction: $M_{\text {personal }}=3.21, S D=1.32$; 
$M_{\text {fictional }}=2.08, S D=1.22 ; t(208)=7.44, p<.0001,95 \%$ CI of the difference: $[0.86,1.48]$,

Cohen's $d=0.61^{1}$.

Table 2.

Directive, Self, and Social Subscales of Functional Significance in Studies 1 and 2

\begin{tabular}{|c|c|c|}
\hline & Study 1 Mean $(S D)$ & Study 2 Mean $(S D)$ \\
\hline \multicolumn{3}{|l|}{ Directive } \\
\hline Personal & $2.71(1.29)$ & $1.83(1.07)$ \\
\hline Fictional & $1.73(1.08)$ & $1.40(0.82)$ \\
\hline \multicolumn{3}{|l|}{ Self } \\
\hline Personal & $3.05(1.25)$ & $2.07(1.22)$ \\
\hline Fictional & $2.06(1.17)$ & $1.38(0.77)$ \\
\hline \multicolumn{3}{|l|}{ Social } \\
\hline Personal & $2.97(1.36)$ & $2.39(1.31)$ \\
\hline Fictional & $1.93(1.17)$ & $1.49(0.90)$ \\
\hline
\end{tabular}

Note. 5-point scale. Differences between personal and fictional

conditions for each subscale are statistically significant $(p s<.001)$.

\section{Functional Significance}

Do people endorse using memories of specific fictional events for functions classically ascribed to autobiographical remembering? Our data suggest that people do, albeit consistently less than for personal memories. Table 2 shows descriptive statistics of the directive, self, and social subscales for Studies 1 and 2. Participants gave lower endorsements for memories of fiction compared to personal memories for the directive function $(95 \% \mathrm{CI}$ of the difference: $[0.64,1.32])$, self function $([0.65,1.34])$, and social function $([0.68,1.40])$. These results are consistent with the pilot study (Supplemental Results) on function, where we administered the

\footnotetext{
${ }^{1}$ A linear mixed effects model modeling participant and individual item as random effects yielded the same conclusions for both Study 1 and Study 2 .
} 
full Talking About Life Experiences (Bluck et al., 2005; Bluck \& Alea, 2011) scale probing personal memories and memories of fiction.

\section{Study 2: Word-Cued Events}

Study 1 examined the phenomenology of well-rehearsed personal memories and memories of fiction, finding that participants fluidly retrieved memories of fiction and experienced those memories similarly to personal memories. In Study 2, we move to eliciting autobiographical memories using word cues, another standard technique of eliciting autobiographical memories (Crovitz \& Schiffman, 1974). We expected this method to yield different types of memories than those in Study 1, given past work establishing that how memories are cued matters (Rubin, 2015; Rubin \& Schulkind, 1997). In this way, we expand the understanding of the phenomenology of memories of fiction we established in Study 1.

\section{Methods}

\section{Participants}

We recruited 52 individuals ( 34 women, $M_{\mathrm{age}}=19.08, S D_{\mathrm{age}}=1.12$ ) from the undergraduate population at Duke University, who completed the study in the lab. The switch to the lab environment was made due to the increased length of the task, as the number of memories to be retrieved and rated increased from two to ten. In addition to the participants described above, one participant was excluded for not following instructions.

\section{Materials}

The materials used in Study 2 were similar to those in Study 1, with two main changes. First, we included additional AMQ items to assess additional properties. We included one item measuring the extent to which each memory elicited the same feelings as when originally 
experienced, two items measuring one's belief in the accuracy of each memory, and one item on spatial imagery. Second, we also adapted the reliving item in the fictional condition to: "When remembering the event, I feel as though I am re-experiencing it as I first read or saw it again.”

\section{Procedure}

Participants were asked to retrieve five personal memories and five memories of fiction, cued by concrete nouns, such as "flower" or "hospital" (Rubin, 1981). They were told that the event retrieved could be closely or loosely connected to the word, and that whatever came to mind was acceptable. Memory cues were presented in two blocks (personal vs. fictional) of five trials each. Whether participants answered questions about personal or fictional events first was randomized.

Otherwise, the instructions and procedures for Study 2 mirrored those of Study 1. Participants provided a description and short label after cueing each event. After all events were cued, participants were reminded of their previous descriptions and rated the qualities of each event.

\section{Results and Discussion}

\section{Memory Contents}

\section{Specificity of Events}

The majority of participants were able to retrieve the five events per condition, retrieving an average of 4.92 personal memories and 4.79 fictional memories. The first author and a trained research assistant coded a randomly selected sample of 200 events (100 of each memory type) using the same coding scheme described in Study 1. Agreement between the two coders was high (90.5\%), and most events across memory types (92.8\%) were specific.

\section{Modality}


When retrieving memories from works of fiction, most participants described events from movies (56\%), with the remaining memories coming from books/novels (16\%), television shows (26\%), and other sources (3\%; e.g. video games).

\section{Temporal Distribution}

On average, events described by participants occurred on 4.39 years prior to the moment of retrieval $\left(M_{\text {personal }}=3.97 ; M_{\text {fiction }}=4.52\right)$. Figure 4 shows the temporal distribution of retrieved memories. As in Study 1, visual inspection reveals that the distribution between personal and fictional memories is quite similar; the shift in average age of the event was likely due to differences in age between participants in Study 1 (AMT) and Study 2 (undergraduates).

\section{Figure 4 .}

Temporal Distribution of Event Memories in Study 2

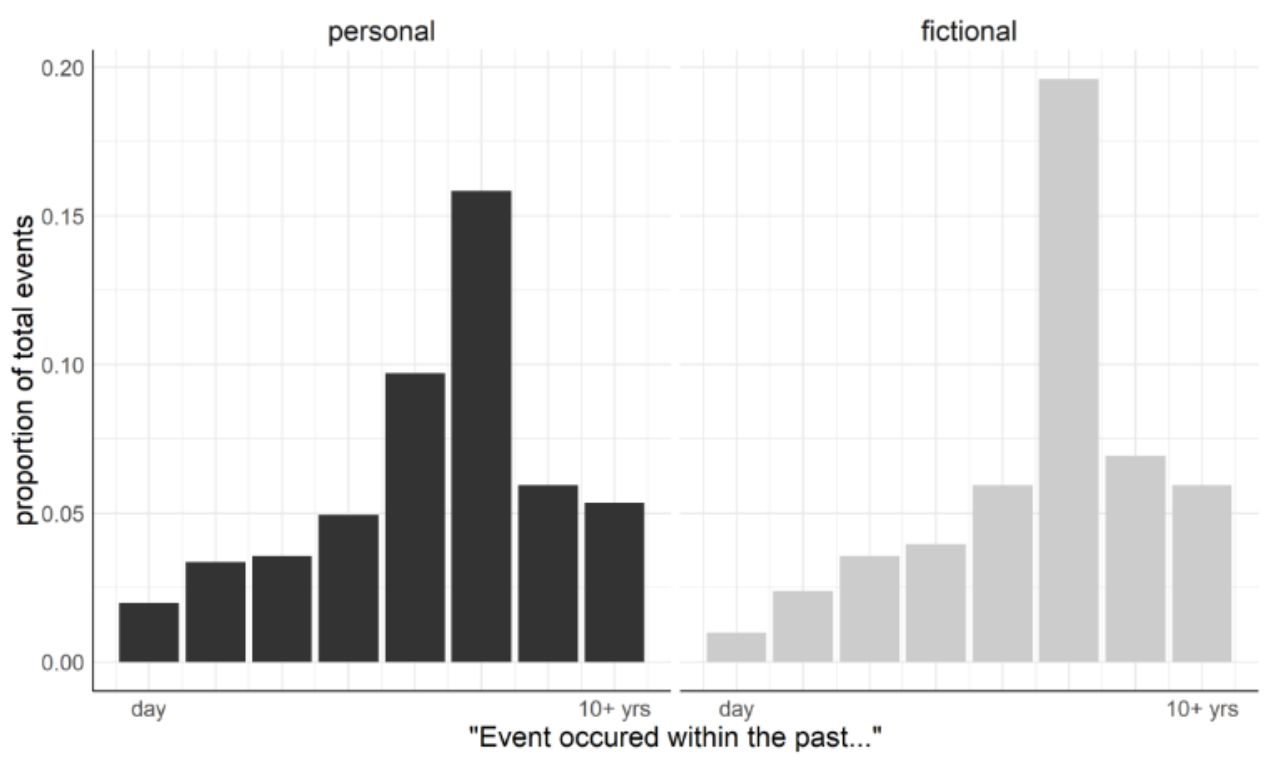

\section{Memory Qualities}

First, we compared potential differences in the AMQ items by memory type (personal or fictional) by computing $t$-tests for each item. The following items showed statistically significant 
differences for memory type (personal versus fiction) after correction for multiple comparisons: rehearsal, visual imagery, spatial layout, reliving, strength of emotions, same feelings again, intensity of emotions, belief (accuracy), and belief (real/testify). Overall, we found that ratings for memories of fiction were consistently lower than personal memories - in contrast to Study 1, where we found that ratings were generally similar.

As in Study 1, we also found that the pattern of ratings across AMQ items was similar. This is visually evidence in panels A and B of Figure 5. Quantitatively, the means of AMQ items for both studies are strongly correlated across fictional and personal conditions: $r=0.93$.

\section{Figure 5.}

Mean Ratings of Phenomenology for Study 2: (A) Dot Plot (B) Radar Plot

(A)

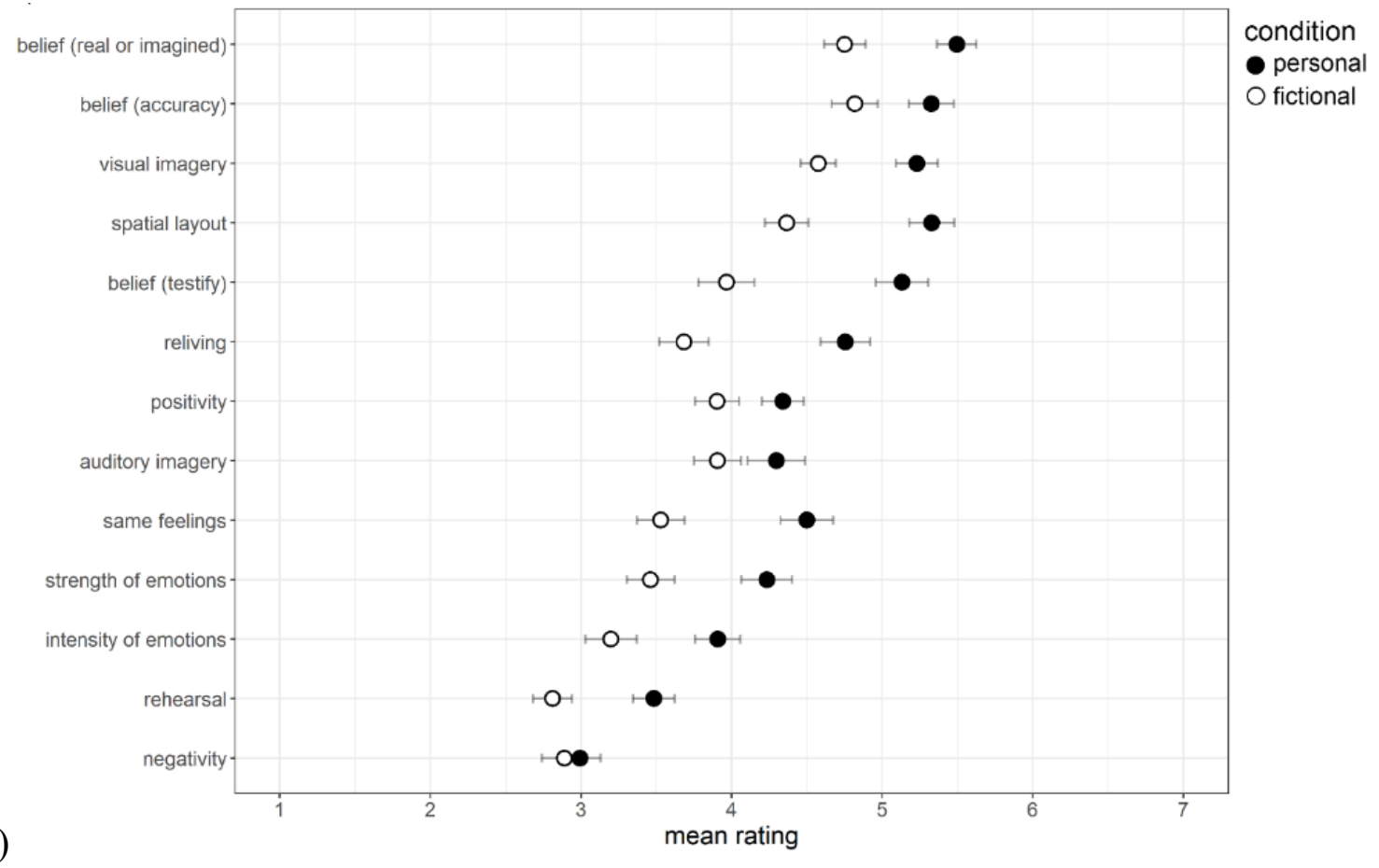




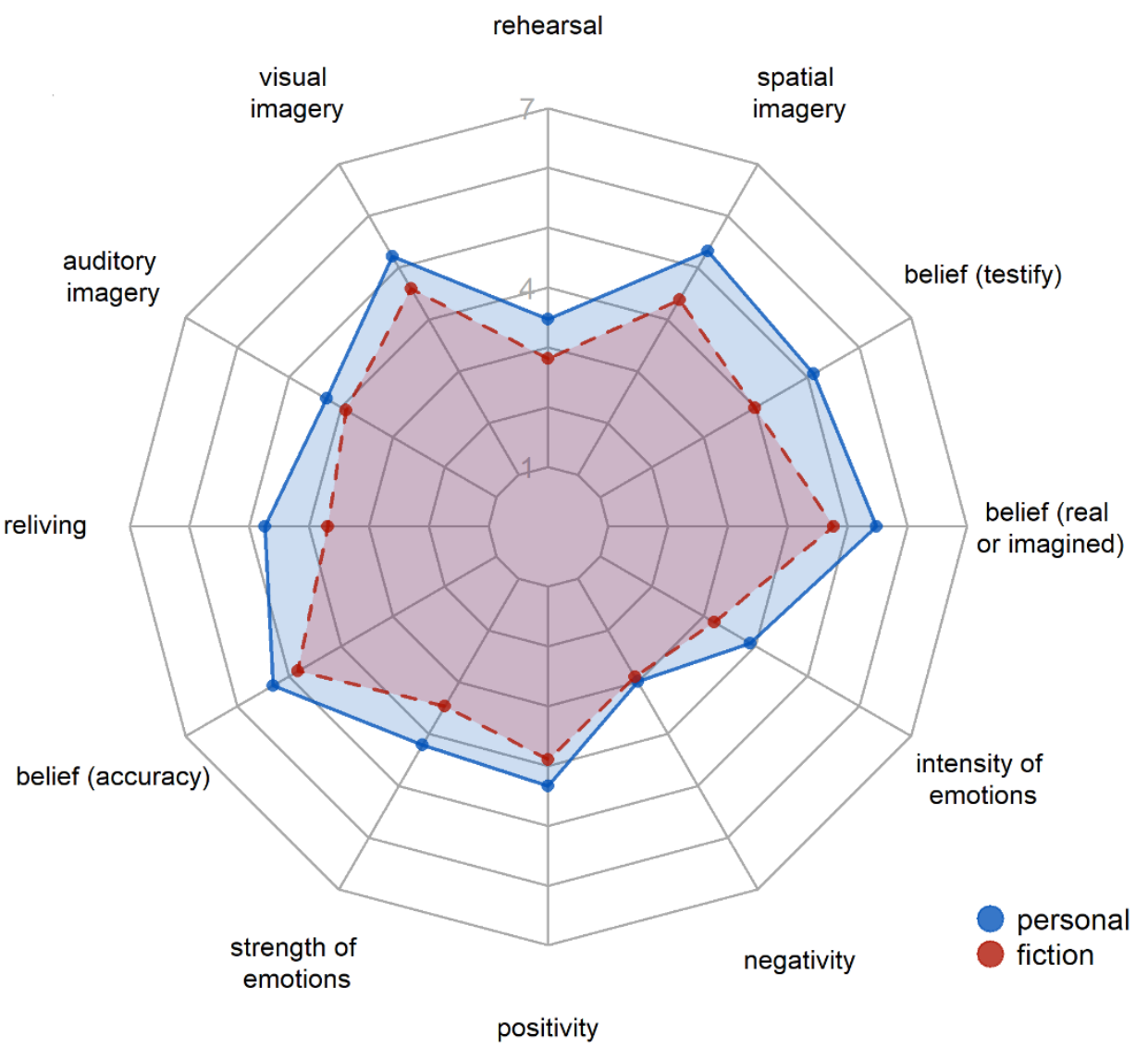

(B)

Note. (A) Error bars represent standard error of the mean. Labeled endpoints of Likert scales indicated that "1" was a low value (e.g, not at all) and "7" was high (e.g,. extremely) (B) Solid and blue lines represent means for personal memories; dotted and red lines represent means for memories of fiction.

\section{Memory Role}

\section{Centrality of Events}

To compare the significance of events, we examined CES scores between personal memories and memories of fiction. The four items showed high reliability: Cronbach's $\alpha=0.91$ $[0.89,0.92]$. We found that participants reported personal memories as more central than memories of fiction: $M_{\text {personal }}=1.88(S D=1.19), M_{\text {fictional }}=1.36(S D=0.78) ; t(508)=6.88, p<$ $.0001,95 \%$ CI of the difference: $[0.39,0.70]$, Cohen's $d=0.61$. 
Qualitatively, events in Study 2 were less likely to represent significant events in participants' lives, compared to Study 1 (Table 1). Representative examples of personal events described in Study 1 include weddings, births of children, and memorable childhood accidents, whereas those cued by nouns in Study 2 were more likely to represent quotidian situations.

\section{Functional Significance}

As in Study 1, participants gave lower endorsements for memories of fiction compared to personal memories for the directive function $(95 \% \mathrm{CI}$ of the difference: $[0.26,0.59])$, self function $([0.51,0.87])$, and social function ([0.70, 1.09]). Table 2 provides descriptive statistics.

\section{Study 3: Childhood and Recent Events}

Studies 1 and 2 provided empirical evidence that memories of fiction elicit vivid phenomenology and hold functional significance in ways that are comparable but not identical to memories of lived experience. In Study 3, we used an experimental manipulation known to affect the vividness of personal memories to assess whether its effects would be similar for memories of fiction. Specifically, we targeted childhood memories, which are likely to be rated as less emotional and detailed than memories of recent events (Chin \& Ward, 2018; Johnson et al., 1988).

Participants generated personal memories and memories of fiction from childhood as well as the recent past, and then reported on the memories' phenomenology, significance, and function. We predicted that people would be able to retrieve memories of fictional events from childhood, given that the two types of memories were similarly distributed across time in previous studies (Figure 2; Figure 4). Less clear was whether there would be forgetting or degradation of memories of fiction, given that they can be re-experienced in a way that lived 
experiences cannot: while lived experiences can be rehearsed in conversation or reviewed via photos they can never literally re-experienced again.

The procedure of Study 3 paralleled that of Study 1, except that half of participants were instructed to retrieve memories from childhood whereas the others retrieved recent memories. Both groups retrieved and described two events, one personal and one fictional, with order randomized across participants. Both groups rated each event on measures relating to phenomenology, significance, and function.

\section{Methods}

\section{Participants}

Participants consisted of 104 individuals (66 women, $M_{\mathrm{age}}=19.20, S D_{\mathrm{age}}=0.99$ ) from the undergraduate population at Duke University and 105 online workers from Amazon Mechanical Turk $\left(51\right.$ women, $\left.M_{\mathrm{age}}=37.98, S D_{\mathrm{age}}=11.48\right)$, resulting in a final sample size of 209 total participants. In this study, $53.2 \%$ of online workers reported at least a bachelor's degree, and $94.7 \%$ reported having taken at least some college courses. We recruited from these two populations, which were used in the previous studies, to maximize the generalizability of our findings. We did not have a priori predictions about differences between memories of fiction and personal memories based on sample, outside of anticipated differences in average participant age.

In addition to those above, we excluded 1 participant from the undergraduate population and 19 participants from the online population for not following directions or giving nonsensical responses. For relevant analyses, we also excluded memories drawn from the incorrect time period; for example, we excluded childhood memories in the condition where participants were 
told to retrieve recent memories. Including these observations does not alter the conclusions drawn.

\section{Materials}

Building and expanding from Studies 1 and 2, we added additional items assessing involuntary/voluntary memory retrieval, as implemented in Rasmussen \& Bernsten (2009). These two new items relating to voluntary and involuntary retrieval were, "Since the event first happened, how often have you willfully thought back to the event in your mind and thought or talked about it?" and "Has the memory of this event suddenly popped up in your thoughts by itself - that is, without your having attempted to remember it?" For consistency with Rasmussen \& Bernsten (2009), we also implemented the four function items used in their work, which were: "I think of this memory in order to handle present or future situations" (directive), "This memory tells me something about my identity" (self), "I have often shared this memory with other people" (social: retrieval), and "This memory gives me a sense of where I belong, and whom I identify with socially and culturally" (social: belonging).

\section{Procedure}

Study 3 had a 2 (recent or childhood) x 2 (personal or fictional) mixed design. Each participant retrieved two memories: one of lived experience and one from a work of fiction. In the recent condition, participants retrieved an event that had "happened recently" or that they had "read or watched recently." In the childhood condition, participants retrieved an event that "happened in your childhood" or that they "read or watched in your childhood." Otherwise, the instructions for retrieving memories were similar to those used in Studies 1 and 2. Thus, all participants retrieved and then described a personal memory and a memory of fiction, and participants were randomized to retrieve events from childhood or recent experience. 


\section{Results and Discussion}

\section{Memory Contents}

\section{Modality}

Most participants described events from movies (45.6\%), followed by events from TV shows (35.6\%), books (16.1\%), and other (2.8\%). Table 3 shows examples of written descriptions for events.

\section{Table 3.}

\section{Examples of Participant Responses in Study 4}

\begin{tabular}{|c|c|c|}
\hline & Memory of Lived Experience & Memory of Fiction \\
\hline $\begin{array}{l}\text { Childhood } \\
\text { Condition }\end{array}$ & $\begin{array}{l}\text { I was sitting at the table in my } \\
\text { grandparents' RV at midnight, eating } \\
\text { Oreos with my grandfather while my } \\
\text { grandmother yelled at my cousin } \\
\text { Andrea for sneaking out of the RV to } \\
\text { meet boys and ruining our vacation. }\end{array}$ & $\begin{array}{l}\text { In the television show Hannah } \\
\text { Montana, there is a scene where she's } \\
\text { singing the song "I Miss You" about } \\
\text { her mother who passed away. She sings } \\
\text { the song out on her back porch while } \\
\text { she looks up at the stars. }\end{array}$ \\
\hline $\begin{array}{l}\text { Recent } \\
\text { Condition }\end{array}$ & $\begin{array}{l}\text { I was working on a software program } \\
\text { and my supervisor looked over my } \\
\text { shoulder and said I was doing well. It } \\
\text { made me feel appreciated and special } \\
\text { because she rarely makes comments } \\
\text { like that. I explained my strategy to } \\
\text { her, and she was very pleased. }\end{array}$ & $\begin{array}{l}\text { A man and a woman were arguing with } \\
\text { each other about attending a birthday } \\
\text { party. During their argument, a blanket } \\
\text { on their bed caught fire. However, } \\
\text { neither of them paid attention to it and } \\
\text { they continued arguing. The discussion } \\
\text { was very high intensity, their voices } \\
\text { were raised, and both people involved } \\
\text { seemed to be very passionate about the } \\
\text { discussion. }\end{array}$ \\
\hline
\end{tabular}

Note. Participant responses were minimally edited for grammar, spelling, and readability.

\section{Temporal Distribution}

We examined the temporal distribution of memories as a manipulation check. As expected, events in the childhood condition were reported to have occurred at an earlier age $(M=$ 
9.84 years) than those in the recent condition $(28.30$ years; $t(375)=19.34, p<.0001)$. This difference was consistent for both personal and fictional conditions, and within both participant populations.

\section{Memory Qualities and Memory Role}

For comparison to Studies 1 and 2, Figure 6A illustrates how personal versus fictional memories differed in their rated phenomenology and Figure 6B illustrates the relationship between items $(r=.96)$. As in Study 2, personal memories were rated on average more highly than memories of fiction on almost all measures. These conclusions were confirmed statistically, as reported in Supplemental Results. We next focus our analysis on the time period manipulation, the focus of Study 3.

\section{Figure 6.}

Mean Ratings of Phenomenology for Study 3: (A) Dot Plot (B) Radar Plot

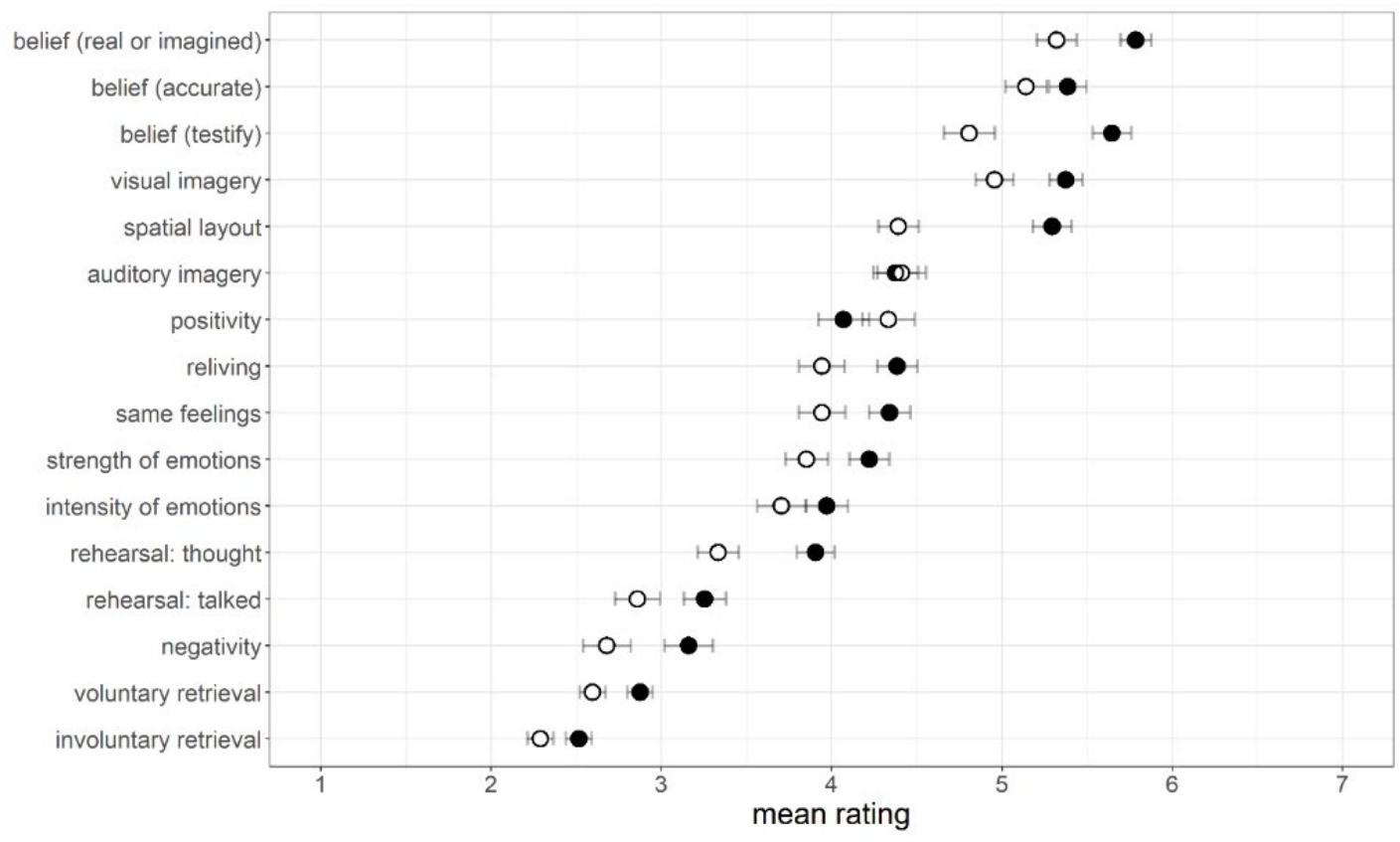

(A) 


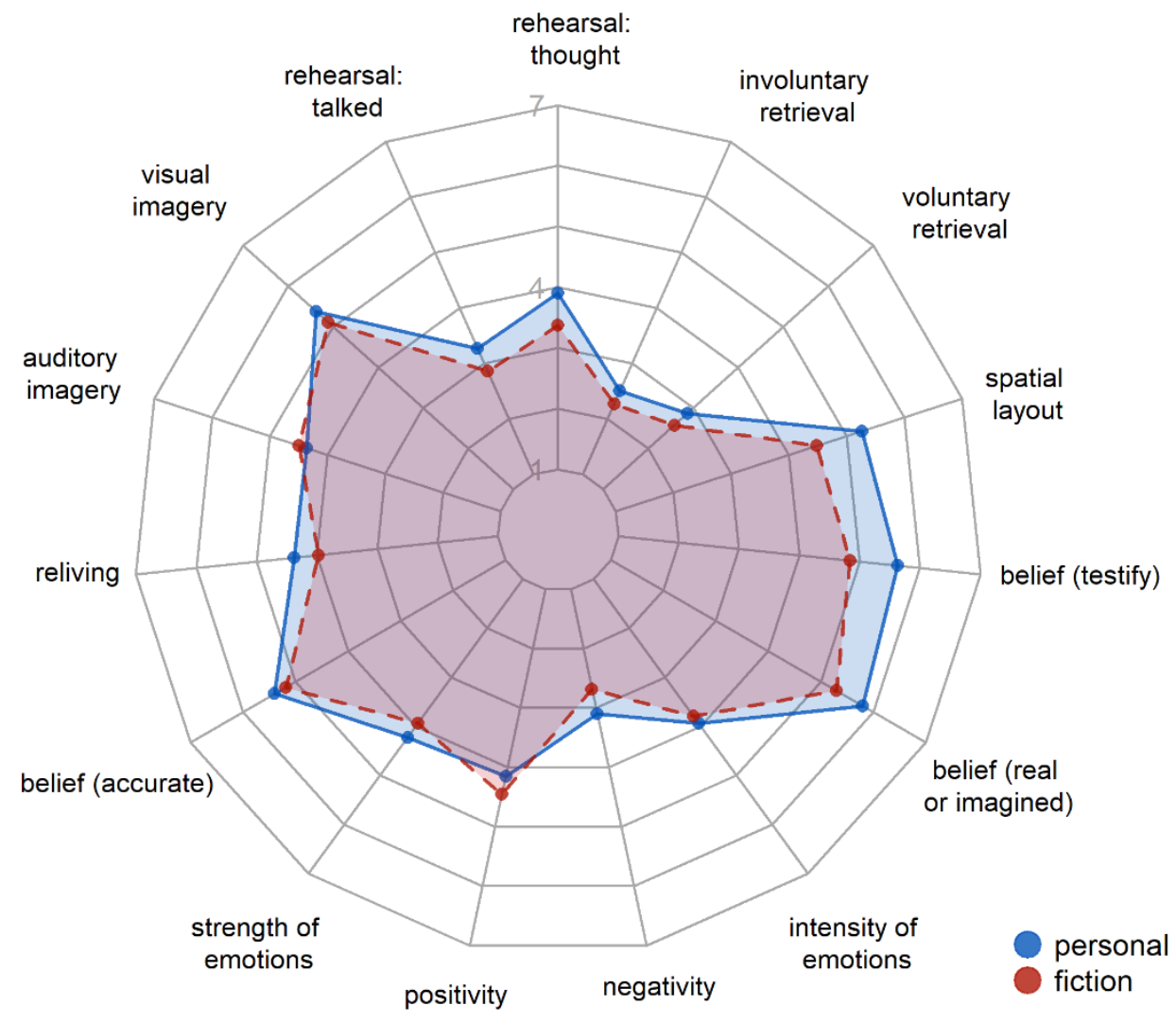

(B)

Note. (A) Error bars represent standard error of the mean. Labeled endpoints of Likert scales indicated that "1" was a low value (e.g,. not at all) and "7" was high (e.g,. extremely) (B) Solid and blue lines represent means for personal memories; dotted and red lines represent means for memories of fiction.

\section{Dimensionality Reduction}

To illuminate the effects of time period broadly - rather than at the level of specific items, as in Studies 1 and 2 - we computed a factor analysis for Study 3. That is, we computed a hypothesis-driven factor analysis on the 27 key dependent measures, which included the AMQ, CES, and TALE items. We identified six latent factors consistent with previous theory and research (Berntsen et al., 2019a; Fitzgerald \& Broadbridge, 2013; Rubin et al., 2019). The six factors were belief, recollection, retrieval, impact, valence, and visual perspective. In the interest 
of brevity, details of this process along with analyses related to visual perspective are reported in Supplemental Results.

We created new dependent measures for the four primary factors (impact, recollection, retrieval, belief) by averaging the relevant items together. To preview the upcoming sections, we found that memories of lived experience showed the expected effects of time period: compared to childhood events, recent personal events were more likely to elicit recollective detail and were more believed. In contrast, memories of fiction did not: childhood memories of fiction were as vivid and believed as recent memories of fiction. After examining results for the factors of belief, recollection, retrieval, impact, and valence, we turn then to offering a hypothesis for why memories of fiction appeared to weather time, namely, that works of fiction can be reexperienced, unlike lived experience.

\section{Belief}

The belief composite variable included items relating to confidence in the accuracy of the memory and willingness to testify about the events in play. We computed a mixed-effects ANOVA with time period (recent vs. childhood) as a between-subjects factor and memory type (personal versus fictional) as a within-subjects factor on "belief." This revealed a main effect of time period $(F(1,211.95)=8.36, p=.004)$, memory type $(F(1,192.93)=32.05, p<.0001)$, as well as a statistically significant interaction $(F(1,192.93)=9.38, p=.003)$.

To interrogate the observed interaction between the time period and memory type, we computed separate $t$-tests for belief for personal and fictional events. We found that for personal events, recent memories were rated as more believed than personal childhood memories, $M_{\text {childhood }}=5.23, S D=1.46 ; M_{\text {recent }}=6.03, S D=1.05 ; t(199)=4.43, p<.0001,95 \% \mathrm{CI}$ of the difference $=[0.44,1.16]$, Cohen's $d=0.63$. However, for memories of fiction, recent and 
childhood memories of fiction were rated as equally believable: $M_{\text {childhood }}=4.98, S D=1.55$; $M_{\text {recent }}=5.12, S D=1.28 ; p=.51,95 \% \mathrm{CI}$ of the difference $=[-0.56,0.28]$.

\section{Recollection}

This recollection composite variable relates to the vivacity or "recollection" of the event and included six measures: strength of emotions, same feelings or atmosphere again, sense of reliving, auditory imagery, visual imagery, and intensity of emotions. We computed a mixedeffects ANOVA with time period (recent versus childhood) as a between-subjects factor and memory type (personal versus fictional) as a within-subjects factor on the "recollection" dependent variable. This revealed a main effect of time period $(F(1,214.60)=7.52, p=.007)$, memory type $(F(1,201.16)=9.50, p=.002)$, as well as a statistically significant interaction $(F(1,201.16)=9.07, p=.003)$

To investigate the observed interaction between time period and memory type, we computed separate $t$-tests for recollection for personal and fictional events. As anticipated, we found that recent memories of personal events were rated higher than childhood memories of personal events on measures of recollection: $M_{\text {childhood }}=4.17, S D=1.45 ; M_{\text {recent }}=4.93, S D=$ $1.12 ; t(199)<.0001,95 \% \mathrm{CI}$ of the difference $=[0.39,1.12]$, Cohen's $d=0.58$. However, this was not true for memories of fiction. Recent and childhood memories from fiction did not differ in recollective detail: $M_{\text {childhood }}=4.17, S D=1.42 ; M_{\text {recent }}=4.22, S D=1.18 ; p=.79,95 \% \mathrm{CI}$ of the difference $=[-0.43,0.33]$. Figure 7 shows the means for each of the individual items of the recollection composite variable, illustrating that this pattern was consistent across individual variables; similar figures for the other composite variables are provided in Supplemental Results for brevity.

\section{Figure 7.}




\section{Recollection of Personal and Fictional Events by Time Period in Study 3}

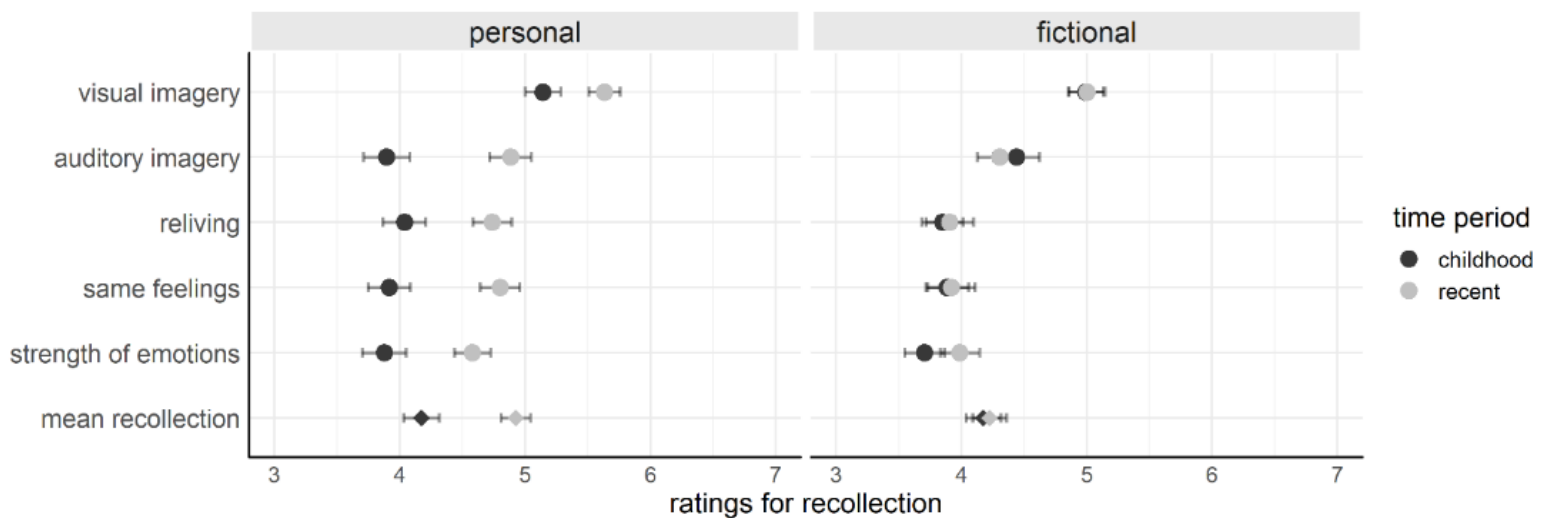

Note. Five items (visual imagery, auditory imagery, reliving, same feelings, strength of emotions) were averaged to create the recollection composite. Means for the composite variable recollection are shown as diamonds on the bottom row.

\section{Retrieval}

This factor relates to the tendency for the memory for be retrieved or rehearsed ("retrieval") and includes measures relating to how often the event is thought about and talked about, as well as how often the memory is retrieved voluntarily or involuntarily. We computed a mixed-effects ANOVA with time (recent versus childhood) as a between subjects-factor and memory type (personal versus fictional) as a within-subjects factor on the retrieval dependent variable. This revealed a main effect of memory type, such that personal memories were rated higher than memories of fiction: $M_{\text {personal }}=3.19, S D=1.27 ; M_{\text {fiction }}=2.75, S D=1.17 ; F(1$, $190.32)=18.36, p<.0001$. The time condition did not reach statistical significance: $M_{\text {childhood }}=$ $2.86, S D=1.15 ; M_{\text {recent }}=3.13, S D=1.33 ; F(1,202.72)=2.96, p=.09$.

We note that our measurement of retrieval for childhood and recent memories in both personal and fictional conditions is restricted by the limitations of the research method and nature of memory: only childhood events that were able to be successfully retrieved in our study 
were able to be included by participants. We speculate that other childhood events not readily retrieved in a laboratory study may show starker effects of time.

\section{Impact}

The factor relates to the dimension of an event's significance or "impact," including all four of the CES items as well as three of the four autobiographical memory function items (directive, self, belong). We computed a mixed-effects ANOVA with time (recent versus childhood) as a between-subjects factor and memory type (personal versus fictional) as a withinsubjects factor on the impact dependent variable. This revealed a main effect of memory type, such that memories of fiction are rated as less significant than personal memories: $M_{\text {personal }}=$ $2.59, S D=1.33 ; M_{\text {fiction }}=1.86, S D=1.11 ; F(1,185.85)=61.99, p<.0001$.

\section{Valence}

We also examined the effect of time period on the factor of valence, or the negativity and positivity associated with the event memory. Given the opposing nature of these items (negative and positive), we analyzed these two items individually, rather than as a composite variable. While personal memories did not differ by valence between childhood and recent memories, memories of fiction from childhood are more positive in nature than recent memories of fiction. This was confirmed by two mixed-effects ANOVAS with time (recent versus childhood) as a between-subjects factor and memory type (personal versus fictional) as a within-subjects factor, predicting positive and negative valence. For the model predicting positive valence, the ANOVA revealed an interaction: $F(1,195.99)=4.66, p=.03$. For the model predicting negative valence, the ANOVA revealed a main effect of memory type $(F(1,202.09)=3.93, p=.03)$ and an interaction $(F(1,202.09)=4.38, p=.04)$. 
To interrogate the observed interactions, we computed $t$-tests for personal and fictional events separately. For personal memories, there was not a statistically significant difference between childhood and recent memories for either positivity or negativity ( $p s>.39)$. For memories of fiction, we found that childhood memories were more positively valenced compared to recent memories: $M_{\text {childhood }}=4.61, S D=1.88 ; M_{\text {recent }}=4.03, S D=1.91, p=.04$, $95 \%$ CI of the difference $=[0.02,1.15]$, Cohen's $d=0.31$. Similarly, we found that childhood memories were less negatively valenced compared to recent memories, although both were rated relatively low on the scale overall: $M_{\text {childhood }}=2.40, S D=1.64 ; M_{\text {recent }}=3.08, S D=1.84, p=.01$, $95 \%$ CI of the difference $=[0.16,1.20]$, Cohen's $d=0.39$. We speculate that this effect of valence may be due to the kinds of fictional media people are permitted to consume in childhood.

\section{Explaining the Effect of Time Period}

Overall, memories of fiction were similar across childhood and recent time conditions, whereas memories of lived experience showed the expected fading of memories over time (Figure 8A). It is unlikely that memories of fiction are unaffected by the passage of time, as laboratory models of memory that use fictional stimuli show clear forgetting effects (Stanhope et al., 1993; Furman et al., 2007). Instead, the results highlight one of the unique qualities of fiction: fictional events can be re-experienced or re-consumed at will, a property distinct from personal events. While personal memories may be rehearsed (i.e., thought or talked about again) and events of a similar nature may be experienced again, it is not currently possible to time travel and re-experience the same exact moment. Thus, we hypothesize that more frequently consumed works of fiction will be rated more highly on measures of phenomenology than works of fiction that were less frequently read or watched. How often a work of fiction has been read or watched 
may explain why memories of fiction are affected differently than personal memories by the passage of time.

Figure 8.

(A) The Effect of Time Period for Belief, Recollection, Retrieval, and Impact in Study 3

(B) Revealing an Effect of Time by Excluding 44 Fictional Events Seen 5+ Times in Study 3

(A)
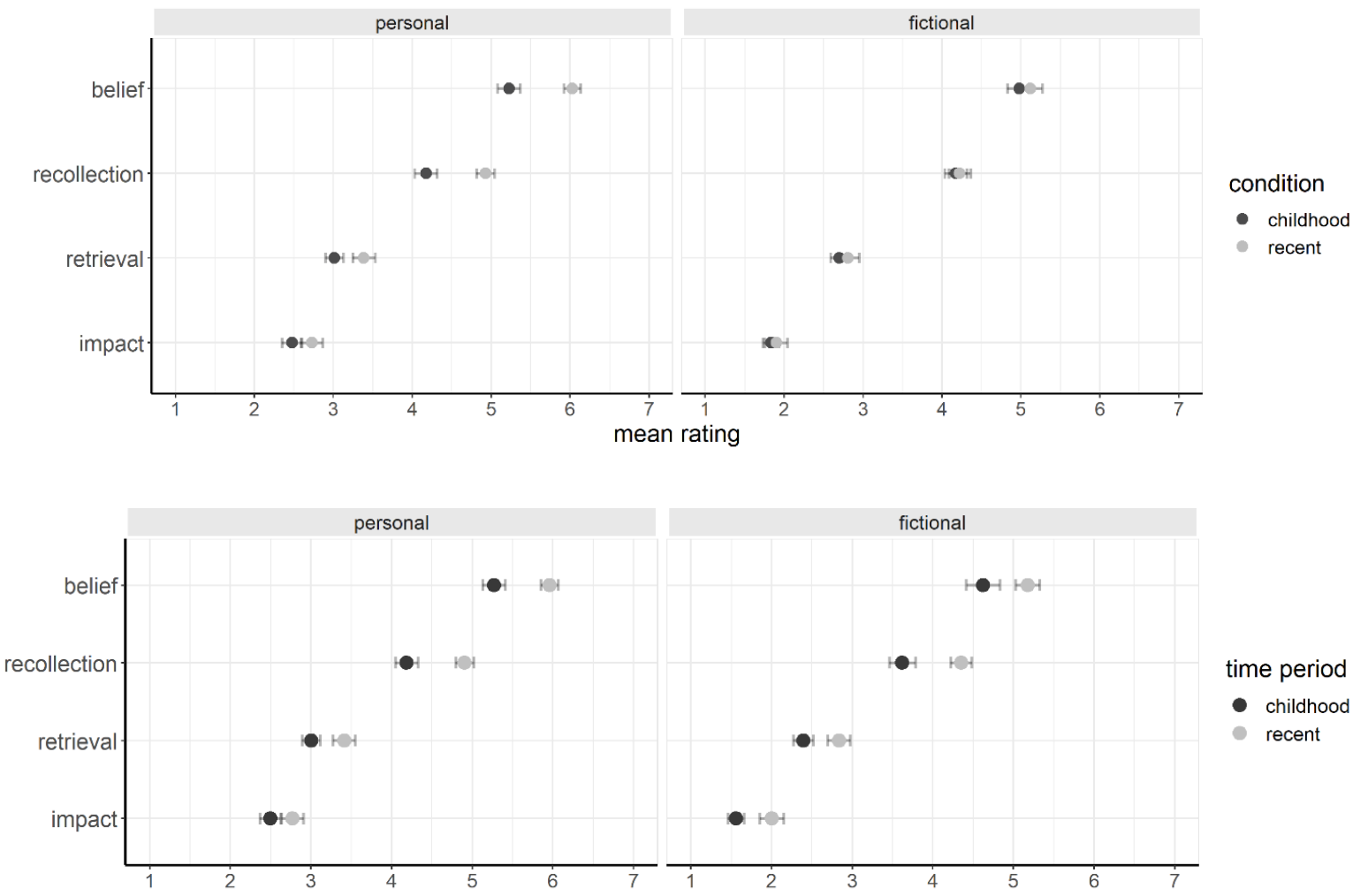

(B)

If the hypothesis described above is true, fictional events that were read or watched more frequently should have higher ratings for impact, recollection, retrieval, and belief. To explore this, we sorted memories of fictional events into three categories based on consumption 
frequency: works of fiction that were read/watched only once $(n=58)$, between two and five times (some; $n=54$ ), and more than five times (many; $n=44)^{2}$.

Next, we computed four separate ANOVAs on each of the dependent variables of interest with consumption frequency as a predictor (consumed once, some, many) for memories of fiction. We found that how often a work of fiction was re-experienced was a statistically significant predictor in all four models: $\operatorname{belief}(F(2,154)=4.35, p=.01)$, recollection $(F(2,154)$ $=12.4, p<.0001)$, retrieval $(F(2,154)=3.45, p=.03)$, and impact $(F(2,154)=3.31, p=.04)$. Post-hoc Tukey multiple comparisons of means indicated that memories of fiction that had been consumed many times were consistently distinct from memories of fiction that had been consumed fewer times, and indeed more similar to the subjective ratings of personal memories (Figure 9).

\footnotetext{
${ }^{2}$ We also examined these data using rehearsal as a continuous variable. However, we found that participant estimates for frequency were not distributed evenly across the scale; once/some/many bins appear to better represent participant estimates of frequency.
} 


\section{Figure 9.}

Consumption Frequency and Memory Qualities (Belief, Recollection, Retrieval, and Impact) Means for Memories of Fiction in Study 3
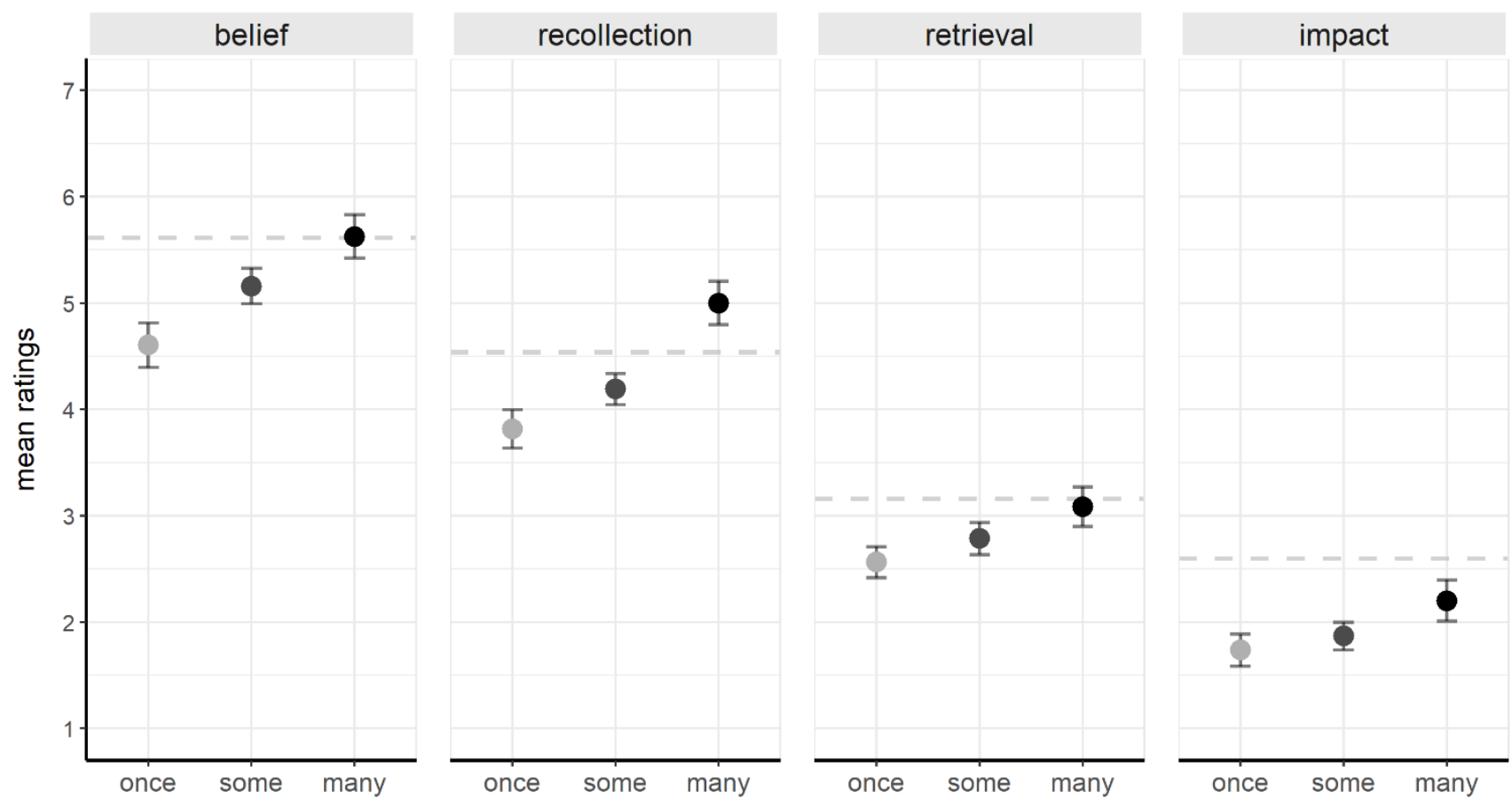

Note. Memories of fiction are shown disaggregated by consumption frequency: once, some (2 to 5 times), and many (more than 5 times). Horizontal dotted line indicates the mean for memories of lived experience.

Lastly, given that consumption frequency explained higher ratings for belief, recollection, retrieval, and impact for memories fiction, we excluded the 44 fictional events $(20.7 \%)$ that had been read or watched 5 or more times. As seen in Figure 8B, this revealed an effect of time period in the expected direction. This conclusion as supported statistically in follow-up $t$-tests on this smaller sample of events, comparing phenomenology for recent and childhood conditions for fictional events for belief $(t(111)=2.19, p=.03)$, recollection $(t(111)=3.03, p=.003))$, and retrieval $(t(111)=2.08, p=.04)$. The difference between recent and childhood events was not 
statistically significant for the impact factor: $t(111)=1.73, p=.09$. To summarize, we found that excluding fictional events that were consumed many times revealed the expected fading across time between childhood and recent events. Overall, we found correlational evidence that consumption frequency explains why memories of fiction did not always exhibit an effect of time period.

\section{General Discussion}

In this work, we formally delineate and characterize the rich phenomenon of memories from works of fiction - such as books, films, and television shows - by situating the study of these memories within the broader landscape of autobiographical memory research. Study 1 examined event memories that were frequently rehearsed and likely to hold a privileged status in people's lives. We found that personal memories and memories of fiction were remembered with comparable levels of recollective vivacity. Study 2 cued memories using concrete nouns and found that memories of fiction were consistently recollected with less vivacity than memories of lived experience. Together, these data suggest that memories of fiction are not typically as vivid or significant as memories of lived experience - but this pattern is a tendency, not a hard and fast rule. In other words, a significant or well-rehearsed event from a work of fiction has the potential to be as vivid or important as some personal memories. For example, the frequently rehearsed memories of fiction in Study 1 were rated lower on the Centrality of Event Scale than experienced events $\left(M_{\text {personal-S1 }}=3.22, M_{\text {fictional-S1 }}=2.08\right)$, but higher than the word-cued personal memories in Study $2\left(M_{\text {personal-S2 }}=1.88\right)$. And even when directly comparing highly rehearsed fictional events to personal ones (which included notable moments such as weddings and the birth of children), $13 \%$ of participants in Study 1 scored their fictional event more central in their lives than their highly rehearsed personal memories. Across Studies 1 and 2, we also found that 
reports of temporal distribution (Figure 2; Figure 4) and subjective experience (Figure 3;

Figure 5) were strikingly similar across studies between memories of lived experiences and of fictional events. These patterns are consistent with the explanation that the differences between remembering memories of lived experiences and remembering fictional events are ones of degree, and that these memory types are expressions of the same underlying system for event memories (Rubin \& Umanath, 2015).

Study 3 highlighted a unique property of memories of fiction: the ability to re-experience them. Beloved sitcoms are rerun for many years, great novels are repeatedly treasured, and children often prefer to watch familiar shows. We found that while memories of fiction appeared to weather time in recollective detail and belief, this pattern was explained by accounting for the number of times the work of fiction had been consumed since childhood (Figure 8; Figure 9). This finding demonstrates the difference between exactly re-experiencing an event (as with works of fiction) and experiencing repeated similar events (e.g., multiple breakfasts, repeated commutes to work): in life, similar events become schematized and blend together, rather than becoming increasingly detailed (Linton, 1982).

The fact that fiction may be re-experienced in a way that lived experience cannot be may have other consequences, such as contributing distinctly to autobiographical memory's social function (Alea \& Bluck, 2003). Multiple individuals can access the same fictional event across time and space, whereas co-presence is typically needed to share a lived experience. Existing research shows that sharing experiences with others amplifies them (Boothby et al., 2014, 2017; Shteynberg et al., 2014), that people are motivated to share experiences to bond with others (Jolly et al., 2019), and that joint attention can foster social closeness in people as well as great apes (Wolf \& Tomasello, 2019). One implication of our work is that people who have shared the 
same fictional or media experiences, even asynchronously, might experience increased social closeness. Indeed, some existing work suggests this may be the case (Gomillion et al., 2017). Future work might expand this asynchronous bonding hypothesis to explore whether, when and why this phenomenon occurs. In general, the functions and purpose of memories of fiction are an interesting direction for future work. Indeed, as we only used previously established items to allow for comparison between personal memories and memories of fiction, which were designed to assess personal memories. Thus, to the extent that the fiction may have unique contributions, these measures do not yet capture them.

However, even re-reading or re-watching the same work of fiction are not identical experiences. For example, one can watch a film first in a theater with friends and subsequently again at home alone, on a smaller screen. While we have investigated memories of fiction as independent units that stand alone, memories of fiction are often nested within personal memories. For example, consider the following personal memory excerpt reported by a participant in Study 1: "Watching Star Wars episode 1 with my family because it was the last movie that my mom had went to see with us as a family." The participant may be reliving aspects of their personal memory: getting in the car to visit the movie theater, sitting in cushioned seats, whether their mom enjoyed the movie, and more. Likely nested within this personal memory are the fictional events of The Phantom Menace, whether it is a vague impression of the movie or specific events from the film. Each memory of fiction has the potential to have this nested structure e.g., flipping the pages of a book on a Sunday morning (level 1) and reading the events which unfolded in the world of said book (level 2). However, one could certainly remember one level without the other. For example, some readers may remember vividly the time and place they read their favorite book, but many others will have 
divorced the personal circumstances from the fictional events. The present work focuses on characterizing the second level, but we note that this structure of memories is potentially unique and is a candidate for future work.

Just as autobiographical memories vary on many dimensions, so do memories of fiction: they may reflect events captured by cameras or prose (Gordon et al., 2009), come from different genres, involve novel or familiar characters (as when one is watching a series or reading a novel), among other differences. To begin to explore one of these factors, we computed exploratory analyses by pooling our data across all three studies for power to examine potential differences between text- and screen-based works of fiction. Details of the full analysis are reported in Supplemental Results. Here we focus on phenomenology, given that the two modalities provide different sensory experiences. We found that screen- and prose-based event memories were rated similarly on measures relating to rehearsal, visual imagery, reliving, strength and intensity of emotions, valence, and accuracy ( $p \underline{\underline{s}}>.28)$, but that screen-based memories of fiction showed higher levels of auditory imagery: $M_{\text {prose }}=3.70, S D=1.93 ; M_{\text {screen }}=$ $4.50, S D=1.67 ; t(126.3)=3.75, p=.0002,95 \% \mathrm{CI}$ of the difference: $[0.38,1.21] . \mathrm{We}$ hypothesize this cross-modality difference is likely due to differences in encoding, as sounds described in texts must be imagined (Alderson-Day et al., 2017; Gunraj \& Klin, 2012; Kurby et al., 2009) and thus are likely more weakly encoded than perceived sounds, consistent with past work on perceived vs. imagined events (Johnson et al., 1988). However, we note that although the physical stimuli (text on a page versus scenes on a screen) differed widely, both screen- and prose-based media exhibited similar levels of phenomenology overall, and that both types of event memories evidenced auditory imagery, consistent with a common form of representation across modality. 
Across studies, we collected data on the functions of memories of fiction, as understanding the purposes such memories serve is an important part of understanding the memory system overall (Hyman \& Faries, 1992). As with our results relating to phenomenology, we found that memories of fiction can serve directive, self, and social functions, albeit typically to a lesser extent than personal memories. Thus, we do not expect that memories of fiction are phenomenologically vivid and important for all. For one, the degree to which people consume fiction and the role that fiction plays in people's lives varies. For example, while $6 \%$ of United States adults report going to the movies one or more times a week, $14 \%$ report never visiting movie theaters at all (Morning Consult, 2018). Secondly, the degree to which people vividly recollect autobiographical memories more generally also represents a meaningful individual difference (Berntsen et al., 2019b; Rubin, 2021b). We do not believe this variation to be a "bug" of the present research topic, but rather suggest that future work may do well to follow William James's advice that if one wants to study religious experience, one should probably observe the most religious man in his most religious moments (James, 1902).

In conclusion, the present project shows that memories for fictional events can and do play an important role in people's lives and should be investigated further as a category of event memory. In the interest of clarity, while we do not propose that the term autobiographical memory be applied to scenes from books and movies, our research suggests that memories of fiction are products of the same underlying system as prototypical autobiographical memories, exhibiting similar properties and functions, and perhaps downstream effects on judgments and behaviors. Remembering, thinking about, and talking about events in narrative fiction are deeply familiar for many. We discuss what movies we watched over the weekend, attend book clubs with dog-eared pages and discussion-ready excerpts, and feel nostalgic for stories consumed in 
childhood. Studying memories of fiction as a phenomenon in its own right can reveal a great deal about the overall nature, properties, and functions of memory. 


\section{References}

Alderson-Day, B., Bernini, M., \& Fernyhough, C. (2017). Uncharted features and dynamics of reading: Voices, characters, and crossing of experiences. Consciousness and Cognition, 49, 98-109. https://doi.org/10.1016/j.concog.2017.01.003

Alea, N., \& Bluck, S. (2003). Why are you telling me that? A conceptual model of the social function of autobiographical memory. Memory, 11(2), 165-178. https://doi.org/10.1080/741938207

Appel, M. (2008). Fictional narratives cultivate just-world beliefs. Journal of Communication, 58(1), 62-83. https://doi.org/10.1111/j.1460-2466.2007.00374.x

Bandura, A. (2006). Going global with social cognitive theory: From prospect to paydirt. In S. I. Donaldson, D. E. Berger, \& K. Pezdek, Applied psychology: New frontiers and rewarding careers. Erlbaum.

http://www.uky.edu/ eushe2/Bandura/Bandura2006Global.pdf

Bates, D., Maechler, M., Bolker, B., \& Walker, S. (2015). Fitting Linear Mixed-Effects Models Using lme4. Journal of Statistical Software, 67(1), 1-48. https://doi.org/10.18637/jss.v067.i01

Berntsen, D., Hoyle, R. H., \& Rubin, D. C. (2019a). The Autobiographical Recollection Test (ART): A Measure of Individual Differences in Autobiographical Memory. Journal of Applied Research in Memory and Cognition, 8(3), 305-318. https://doi.org/10.1016/j.jarmac.2019.06.005

Berntsen, D., Hoyle, R. H., \& Rubin, D. C. (2019b). The Autobiographical Recollection Test (ART): A Measure of Individual Differences in Autobiographical Memory. Journal of Applied Research in Memory and Cognition, 8(3), 305-318. https://doi.org/10.1016/j.jarmac.2019.06.005

Berntsen, D., \& Rubin, D. C. (2006). The centrality of event scale: A measure of integrating a trauma into one's identity and its relation to post-traumatic stress disorder symptoms. Behaviour Research and Therapy, 44(2), 219-231. https://doi.org/10.1016/j.brat.2005.01.009 
Billington, J. (2011). "Reading for Life": Prison Reading Groups in Practice and Theory. Critical Survey, 23(3), 67-85.

Black, J., \& Barnes, J. L. (2015). Fiction and social cognition: The effect of viewing awardwinning television dramas on theory of mind. Psychology of Aesthetics, Creativity, and the Arts, 9(4), 423-429. https://doi.org/10.1037/aca0000031

Bluck, S. (2003). Autobiographical memory: Exploring its functions in everyday life. Memory, 11(2), 113-123. https://doi.org/10.1080/741938206

Bluck, S., \& Alea, N. (2011). Crafting the TALE: Construction of a measure to assess the functions of autobiographical remembering. Memory, 19(5), 470-486. https://doi.org/10.1080/09658211.2011.590500

Bluck, S., Alea, N., Habermas, T., \& Rubin, D. C. (2005). A tale of three functions: The selfreported uses of autobiographical memory. Social Cognition, 23(1), 91.

Boothby, E. J., Clark, M. S., \& Bargh, J. A. (2014). Shared Experiences Are Amplified. Psychological Science, 25(12), 2209-2216. https://doi.org/10.1177/0956797614551162

Boothby, E. J., Smith, L. K., Clark, M. S., \& Bargh, J. A. (2017). The world looks better together: How close others enhance our visual experiences: Sharing visual experiences with close others. Personal Relationships, 24(3), 694-714. https://doi.org/10.1111/pere.12201

Boyd, B. (2009). On the Origin of Stories. Harvard University Press.

Butler, A. C., Zaromb, F. M., Lyle, K. B., \& Roediger, H. L. (2009). Using popular films to enhance classroom learning the good, the bad, and the interesting. Psychological Science, 20(9), 1161-1168.

Chin, T., \& Ward, J. (2018). Synaesthesia is linked to more vivid and detailed content of autobiographical memories and less fading of childhood memories. Memory, 26(6), 844851. https://doi.org/10.1080/09658211.2017.1414849

Crovitz, H. F., \& Schiffman, H. (1974). Frequency of episodic memories as a function of their age. Bulletin of the Psychonomic Society, 4(5), 517-518. 
Cuijpers, P. (1997). Bibliotherapy in unipolar depression: A meta-analysis. Journal of Behavior Therapy and Experimental Psychiatry, 28(2), 139-147. https://doi.org/10.1016/S00057916(97)00005-0

De Brigard, F., Giovanello, K. S., Stewart, G. W., Lockrow, A. W., O’Brien, M. M., \& Spreng, N. R. (2016). Characterizing the subjective experience of episodic past, future, and counterfactual thinking in healthy younger and older adults. The Quarterly Journal of Experimental Psychology, 1-18. https://doi.org/10.1080/17470218.2015.1115529

Fitzgerald, J. M., \& Broadbridge, C. L. (2013). Latent constructs of the Autobiographical Memory Questionnaire: A recollection-belief model of autobiographical experience. Memory, 21(2).

https://www.tandfonline.com/doi/full/10.1080/09658211.2012.725736?casa_token=UMk wFftKs0wAAAAA:M_99u12e6Bd_k54aRctKOQENs2pd7f8D3EQ0zON67zsh4UIs8Sw 6sjZlBBYrc8kqpbGZde0NSdkX

Furman, O., Dorfman, N., Hasson, U., Davachi, L., \& Dudai, Y. (2007). They saw a movie: Long-term memory for an extended audiovisual narrative. Learning \& Memory, 14(6), 457-467. https://doi.org/10.1101/1m.550407

Gernsbacher, M. A., Varner, K. R., \& Faust, M. E. (1990). Investigating Differences in General Comprehension Skill. Journal of Experimental Psychology. Learning, Memory, and Cognition, 16(3), 430-445.

Gomillion, S., Gabriel, S., Kawakami, K., \& Young, A. F. (2017). Let's stay home and watch TV: The benefits of shared media use for close relationships. Journal of Social and Personal Relationships, 34(6), 855-874. https://doi.org/10.1177/0265407516660388

Gordon, R., Gerrig, R. J., \& Franklin, N. (2009). Qualitative Characteristics of Memories for Real, Imagined, and Media-Based Events. Discourse Processes, 46(1), 70-91. https://doi.org/10.1080/01638530802629117

Green, M. C., \& Brock, T. C. (2000). The role of transportation in the persuasiveness of public narratives. Journal of Personality and Social Psychology, 79(5), 701-721. https://doi.org/10.1037/0022-3514.79.5.701 
Green, M. C., Strange, J. J., \& Brock, T. C. (2003). Narrative Impact: Social and Cognitive Foundations. Taylor \& Francis.

Gunraj, D. N., \& Klin, C. M. (2012). Hearing Story Characters' Voices: Auditory Imagery During Reading. Discourse Processes, 49(2), 137-153. https://doi.org/10.1080/0163853X.2012.657755

Hyman, I. E., \& Faries, J. M. (1992). The Functions of Autobiographical Memory. In M. A. Conway, D. C. Rubin, H. Spinnler, \& W. A. Wagenaar (Eds.), Theoretical Perspectives on Autobiographical Memory (pp. 207-221). Kluwer Academic Publishers.

James, W. (1902). The Varieties of Religious Experience. http://xroads.virginia.edu/ hyper/wjames/ch02.html

Johnson, M. J., Foley, M. A., Suengas, A. G., \& Raye, C. L. (1988). Phenomenal Characteristics of Memories for Perceived and Imagined Autobiographical Events. Journal of Experimental Psychology: General, 117(4), 371-376.

Johnson, M. K. (1988). Reality Monitoring: An Experimental Phenomenological Approach. Journal of Experimental Psychology: General, 117(4), 390-394.

Johnson-Laird, P. N. (1983). Mental Models: Towards a Cognitive Science of Language, Inference, and Consciousness. Harvard University Press.

Jolly, E., Tamir, D. I., Burum, B., \& Mitchell, J. P. (2019). Wanting without enjoying: The social value of sharing experiences. PLOS ONE, 14(4), e0215318. https://doi.org/10.1371/journal.pone.0215318

Kensinger, E. A., \& Schacter, D. L. (2006). Neural Processes Underlying Memory Attribution on a Reality-monitoring Task. Cerebral Cortex, 16(8), 1126-1133. https://doi.org/10.1093/cercor/bhj054

Kidd, D. C., \& Castano, E. (2013). Reading Literary Fiction Improves Theory of Mind. Science, 342(6156), 377-380. https://doi.org/10.1126/science.1239918

Kintsch, W., \& Van Dijk, T. A. (1978). Toward a model of text comprehension and production. Psychological Review, 85(5), 363. 
Knippels, M.-C., Severiens, S. E., \& Klop, T. (2009). Education through fiction: acquiring opinion-forming skills in the context of genomics. International Journal of Science Education, 31(15), 2057-2083. https://doi.org/10.1080/09500690802345888

Kurby, C. A., Magliano, J. P., \& Rapp, D. N. (2009). Those voices in your head: Activation of auditory images during reading. Cognition, 112(3), 457-461. https://doi.org/10.1016/j.cognition.2009.05.007

Kuznetsova, A., Brockhoff, P., \& Christensen, R. (2017). lmerTest Package: Tests in Linear Mixed Effects Models. Journal of Statistical Software, 82(13), 1-25.

L. Varga, N., Gaugler, T., \& Talarico, J. (2019). Are mnemonic failures and benefits two sides of the same coin?: Investigating the real-world consequences of individual differences in memory integration. Memory \& Cognition. https://doi.org/10.3758/s13421-018-0887-4

Larsen, S. F. (1988). Remembering without experiencing: Memory for reported events. In Remembering reconsidered: Ecological and traditional approaches to the study of memory (pp. 326-355). Cambridge University Press. https://doi.org/10.1017/CBO9780511664014.014

Larsen, S. F., \& Plunkett, K. (1987). Remembering experienced and reported events. Applied Cognitive Psychology, 1(1).

Linton, M. (1982). Transformations of memory in everyday life. In Memory Observed: Remembering in Natural Contexts (pp. 107-118). W. H. Freeman.

Loftus, E. F. (2005). Planting misinformation in the human mind: A 30-year investigation of the malleability of memory. Learning \& Memory, 12(4), 361-366. https://doi.org/10.1101/lm.94705

Loftus, E. F., \& Pickrell, J. E. (1995). The formation of false memories. Psychiatric Annals, 25(12), 720-725.

Magliano, J. P., Miller, J., \& Zwaan, R. A. (2001). Indexing space and time in film understanding. Applied Cognitive Psychology, 15(5), 533-545. https://doi.org/10.1002/acp.724 
Magliano, J. P., Radvansky, G. A., \& Copeland, D. E. (2012). Beyond Language Comprehension: Situation Models as a Form of Autobiographical Memory. In F. Schmalhofer \& C. A. Perfetti (Eds.), Higher Level Language Processes in the Brain: Inference and Comprehension Processes (pp. 379-391). Lawrence Erlbaum Associates.

Magliano, J. P., Radvansky, G. A., Forsythe, J. C., \& Copeland, D. E. (2014). Event segmentation during first-person continuous events. Journal of Cognitive Psychology, 26(6), 649-661. https://doi.org/10.1080/20445911.2014.930042

Marsh, E. J., Butler, A. C., \& Umanath, S. (2012). Using Fictional Sources in the Classroom: Applications from Cognitive Psychology. Educational Psychology Review, 24(3), 449469. https://doi.org/10.1007/s10648-012-9204-0

Marsh, E. J., Meade, M. L., \& Roediger, H. L. R. (2003). Learning facts from fiction. Journal of Memory and Language, 49(4), 519-536. https://doi.org/10.1016/S0749-596X(03)000925

McDaniel, M. A., Marsh, E. J., \& Gouravajhala, R. (in press). Individual Differences in Structure Building: Impacts on Comprehension and Learning, Theoretical Underpinnings, and Supports for Less-Able Structure Builders. Perspectives on Psychological Science.

Morgan, M., \& Shanahan, J. (2010). The State of Cultivation Invited Essay. Journal of Broadcasting \& Electronic Media, 54, 337-356.

Morning Consult. (2018). National Tracking Poll \#181026 (p. 146).

Nakazawa, M. (2019). fmsb: Functions for Medical Statistics Book with some Demographic Data (Version R package version 0.7.0) [Computer software]. https://CRAN.Rproject.org/package $=$ fmsb

Newell, A. (1973). You can't play 20 questions with nature and win: Projective comments on the papers of this symposium. In W. G. Chase (Ed.), Visual information processing (pp. 283308). Academic Press.

Otgaar, H., Scoboria, A., \& Mazzoni, G. (2014). On the Existence and Implications of Nonbelieved Memories. Current Directions in Psychological Science, 23(5), 349-354. https://doi.org/10.1177/0963721414542102 
Pillemer, D. B. (2003). Directive functions of autobiographical memory: The guiding power of the specific episode. Memory, 11(2), 193-202. https://doi.org/10.1080/741938208

Pillemer, D. B., Rhinehart, E. D., \& White, S. H. (1986). Memories of Life Transitions: The First Year in College. Human Learning, 5, 109-123.

Pillemer, D. B., Steiner, K. L., Kuwabara, K. J., Thomsen, D. K., \& Svob, C. (2015). Vicarious memories. Consciousness and Cognition, 36, 233-245. https://doi.org/10.1016/j.concog.2015.06.010

Potts, G. R., \& Peterson, S. B. (1985). Incorporation versus Compartmentalization in Memory for Discourse. Journal of Memory and Language; New York, 24(1), 107-118.

Potts, G. R., St. John, M. F., \& Kirson, D. (1989). Incorporating new information into existing world knowledge. Cognitive Psychology, 21(3), 303-333. https://doi.org/10.1016/00100285(89)90011-X

Radvansky, G. A., \& Copeland, D. E. (2006). Situation models and retrieval interference: Pictures and words. Memory, 14(5), 614-623. https://doi.org/10.1080/09658210600647714

Rasmussen, A. S., \& Berntsen, D. (2009). Emotional valence and the functions of autobiographical memories: Positive and negative memories serve different functions. Memory \& Cognition, 37(4), 477-492. https://doi.org/10.3758/MC.37.4.477

RStudio Team. (2018). RStudio: Integrated Development for $R$ (RStudio.Version()) [Computer software]. RStudio, Inc. http://www.rstudio.com/

Rubin, D. C. (1981). Norms for 34 properties of 125 words. JSAS Catalog of Selected Documents in Psychology, 11.

Rubin, D. C. (2015). One bump, two bumps, three bumps, four? Using retrieval cues to divide one autobiographical memory reminiscence bump into many. Journal of Applied Research in Memory and Cognition, 4(1), 87-89. https://doi.org/10.1016/j.jarmac.2014.12.005 
Rubin, D. C. (2021a). A conceptual space for episodic and semantic memory. Memory \& Cognition. https://doi.org/10.3758/s13421-021-01148-3

Rubin, D. C. (2021b). Properties of autobiographical memories are reliable and stable individual differences. Cognition, 210, 104583. https://doi.org/10.1016/j.cognition.2021.104583

Rubin, D. C., Deffler, S. A., \& Umanath, S. (2019). Scenes enable a sense of reliving: Implications for autobiographical memory. Cognition, 183, 44-56. https://doi.org/10.1016/j.cognition.2018.10.024

Rubin, D. C., Schrauf, R. W., \& Greenberg, D. L. (2003). Belief and recollection of autobiographical memories. Memory \& Cognition, 31(6), 887-901. https://doi.org/10.3758/BF03196443

Rubin, D. C., \& Schulkind, M. D. (1997). Distribution of important and word-cued autobiographical memories in 20-, 35-, and 70-year-old adults. Psychology and Aging, $12(3), 524$.

Rubin, D. C., \& Umanath, S. (2015). Event memory: A theory of memory for laboratory, autobiographical, and fictional events. Psychological Review, 122(1), 1-23. https://doi.org/10.1037/a0037907

Rubin, D. C., Wetzler, S. E., \& Nebes, R. D. (1986). Autobiographical memory across the adult lifespan. In D. C. Rubin (Ed.), Autobiographical Memory (pp. 202-221). Cambridge University Press.

Schacter, D. L., \& Addis, D. R. (2007). The cognitive neuroscience of constructive memory: remembering the past and imagining the future. Philosophical Transactions of the Royal Society B: Biological Sciences, 362(1481), 773-786. https://doi.org/10.1098/rstb.2007.2087

Schacter, D. L., Benoit, R. G., De Brigard, F., \& Szpunar, K. K. (2015). Episodic future thinking and episodic counterfactual thinking: intersections between memory and decisions. Neurobiology of Learning and Memory, 117, 14-21. http://dx.doi.org.proxy.lib.duke.edu/10.1016/j.nlm.2013.12.008 
Schacter, D. L., Guerin, S. A., \& St. Jacques, P. L. (2011). Memory distortion: an adaptive perspective. Trends in Cognitive Sciences, 15(10), 467-474. https://doi.org/10.1016/j.tics.2011.08.004

Scoboria, A., Jackson, D. L., Talarico, J., Hanczakowski, M., Wysman, L., \& Mazzoni, G. (2014). The role of belief in occurrence within autobiographical memory. Journal of Experimental Psychology: General, 143(3), 1242-1258.

https://doi.org/10.1037/a0034110

Scoboria, A., Memon, A., Gawrylowicz, J., \& Clark, A. (2015). Nonbelieved memories across the adult lifespan. Psychology of Consciousness: Theory, Research, and Practice, 2(4), 461.

Shanahan, J., \& Morgan, M. (1999). Television and its Viewers: Cultivation Theory and Research. Cambridge University Press. https://doi.org/10.1017/CBO9780511488924

Shteynberg, G., Hirsh, J. B., Apfelbaum, E. P., Larsen, J. T., Galinsky, A. D., \& Roese, N. J. (2014). Feeling more together: Group attention intensifies emotion. Emotion, 14(6), 1102-1114. https://doi.org/10.1037/a0037697

Stanhope, N., Cohen, G., \& Conway, M. (1993). Very long-term retention of a novel. Applied Cognitive Psychology, 7(3), 239-256.

Thomsen, D. K., \& Pillemer, D. B. (2017). I know my story and I know your story: Developing a conceptual framework for vicarious life stories. Journal of Personality, 85, 464-480. https://doi.org/10.1111/jopy.12253

Torchiano, M. (2020). Effsize: Efficient Effect Size Computation (Version R package version 0.8.1) [Computer software]. 10.5281/zenodo.1480624

Tulving, E. (1985). Memory and consciousness. Canadian Psychology, 26(1), 1-12.

Wickham, H. (2016). ggplot2: Elegant Graphics for Data Analysis. Springer-Verlag. https://ggplot2.tidyverse.org

Wolf, W., \& Tomasello, M. (2019). Visually attending to a video together facilitates great ape social closeness. Proceedings of the Royal Society. 
Yang, B. W., Deffler, S. A., Marsh, E. J. (2020). A Comparison of Memories of Fiction and Autobiographical Memories. Retrieved from osf.io/m2aew

Zwaan, R. A. (1999). Situation models: The mental leap into imagined worlds. Current Directions in Psychological Science, 8(1), 15-18.

Zwaan, R. A., Langston, M. C., \& Graesser, A. C. (1995). The Construction of Situation Models in Narrative Comprehension: An Event-Indexing Model. Psychological Science, 6(5), 292-297. 
Supplemental Results 


\section{Contents}

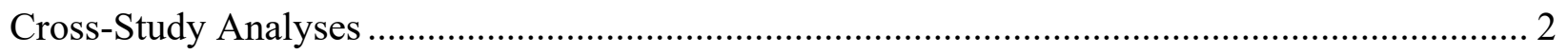

Effects of Modality on Phenomenology (AMQ) …………................................................. 2

Effects of Modality on Memory Role (Centrality and Function) ................................................ 3

Pilot: Function of Personal Memories and Memories of Fiction.................................................... 4

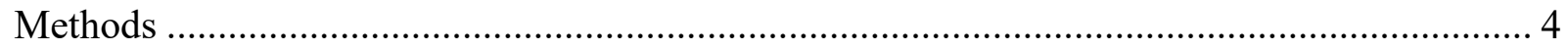

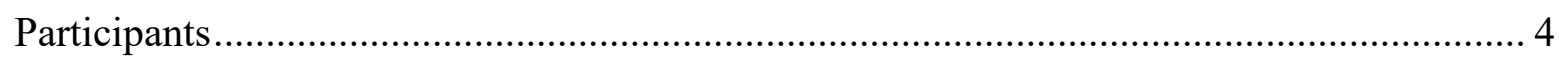

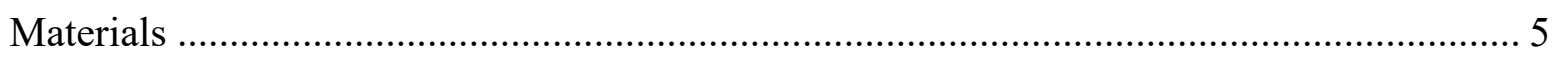

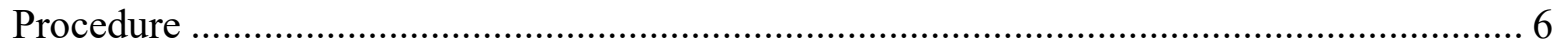

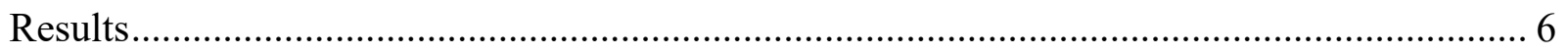

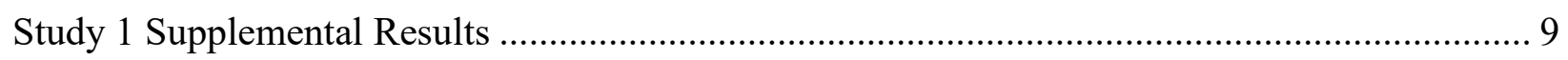

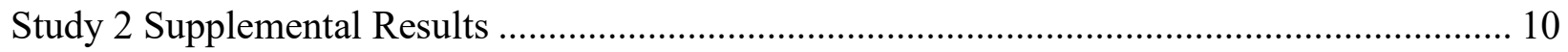

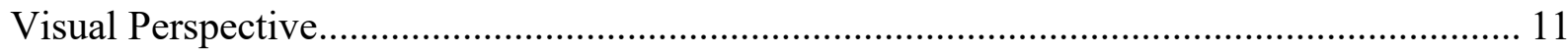

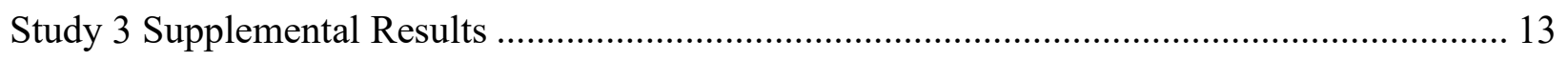

Dimensionality Reduction: Factor Analysis Details............................................................ 13

Exploratory Factor Analysis ............................................................................................. 14

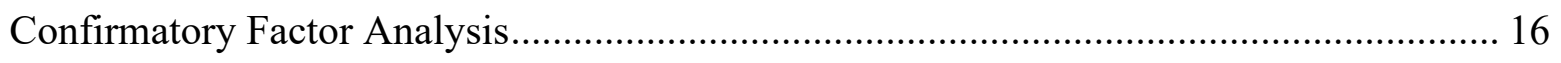

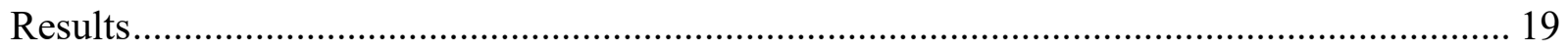

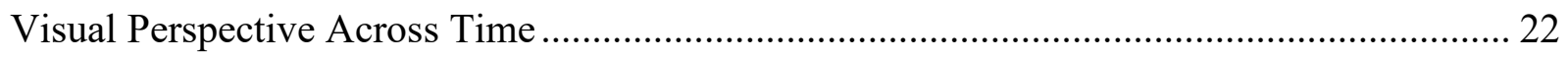




\section{Cross-Study Analyses}

To explore potential effects of modality, we combined data from Studies 1, 2, and 3 to increase power ( $n=578$ observations). We note that these analyses are exploratory and that these data were heavily skewed towards screen-based media: $51.2 \%$ movies, $28.5 \%$ TV shows, $16.6 \%$ book or novel, and $3.7 \%$ other or not reported.

\section{Effects of Modality on Phenomenology (AMQ)}

Do we find evidence of phenomenological differences between screen- and prose-based media? In this exploratory analysis, we first computed a multivariate analysis of variance (MANOVA) using the 9 measures common to all three studies as dependent variables (accuracy, see, hear, emotion, intensity, rehearsal, positivity, negativity, reliving) and modality (proseversus screen-based media) and study (1,2, or 3) as crossed independent variables. This analysis revealed statistically significant effects of modality media $(M A T S=16.48, p<.001)$ and study $(M A T S=195.58, p<.001)$.

Since phenomenology differences by study were expected, we set the study effect aside. We next computed follow-up $t$-tests ${ }^{1}$ for each AMQ item by modality ${ }^{2}$. We found that the difference between prose- and screen-based media was driven by a statistically significant difference in auditory imagery, such that screen-based media showed higher levels of auditory imagery: $M_{\text {prose }}=3.70, M_{\text {screen }}=4.49$.

\footnotetext{
${ }^{1}$ Computing Wilcoxon Rank Sum tests yields the same conclusions.

${ }^{2}$ In these exploratory and supplemental analyses, we do not correct for multiple comparisons. However, we provide $p$-values, allowing for Bonferroni correction.
} 


\section{Table S1.}

\section{Comparing AMQ items for Prose- versus Screen-Based Media}

\begin{tabular}{lcccc}
\hline Item & $\begin{array}{c}\text { Prose } \\
\text { Mean (SD) }\end{array}$ & $\begin{array}{c}\text { Screen } \\
\text { Mean (SD) }\end{array}$ & $t$ & $p$-value \\
\hline Rehearsal & $3.32(1.62)$ & $3.27(1.74)$ & 0.20 & .84 \\
Visual imagery & $4.99(1.35)$ & $4.97(1.41)$ & 0.12 & .91 \\
Auditory imagery & $3.70(1.93)$ & $4.50(1.67)$ & $3.75^{* * *}$ & .0002 \\
Reliving & $5.01(1.72)$ & $5.19(1.69)$ & 1.08 & .28 \\
Same strength of emotions & $4.03(1.54)$ & $3.87(1.68)$ & 0.92 & .36 \\
Intensity of emotions & $3.81(1.74)$ & $3.63(1.83)$ & 0.93 & .35 \\
Valence: positivity & $4.17(1.82)$ & $4.20(1.89)$ & 0.17 & .86 \\
Valence: negativity & $2.95(1.82)$ & $2.84(1.86)$ & 0.51 & .61 \\
Accuracy & $5.01(1.45)$ & $5.19(1.45)$ & 1.08 & .28 \\
\hline
\end{tabular}

\section{Effects of Modality on Memory Role (Centrality and Function)}

Do we find evidence of differences in memory role between screen- and prose-based media? We computed $t$-tests on the three function subscales (directive, self, social) and CES (averaged across 4 items). We found that all prose-based media means were higher than screenbased media means. This difference was statistically significant for the self function and CES. We speculate that this difference is driven by content differences by media, but do not have firm hypotheses to explain this differences; this point is a candidate for future work.

\section{Table S2.}

Comparing CES and Function items for Prose- Versus Screen-Based Media

\begin{tabular}{lcccc}
\hline Item & Prose Mean (SD) & Screen Mean (SD) & $t$ & $p$-value \\
\hline Function: Directive & $1.86(1.32)$ & $1.60(1.18)$ & 1.82 & .07 \\
Function: Self & $2.22(1.53)$ & $1.81(1.37)$ & $2.42^{*}$ & .02 \\
Function: Social & $2.23(1.45)$ & $1.99(1.49)$ & 1.41 & .16 \\
CES & $2.05(1.09)$ & $1.52(0.84)$ & $4.50^{* * *}$ & $<.0001$ \\
\hline
\end{tabular}




\section{Pilot: Function of Personal Memories and Memories of Fiction}

To directly compare how people report using memories of fiction and autobiographical memories, we adapted the Thinking About Life Experiences (TALE) questionnaire, a previously validated survey used to assess theoretically motivated memory functions across the lifespan (Bluck, 2003; Bluck et al., 2005). We hypothesized that people would report utilizing both personal memories and memories of fiction for directive, self, and social functions, but that reported frequencies would be higher for personal memories than for memories of fiction. Additionally, previous work suggests that engaging in fictional narratives may serve to simulate social experience (Mar \& Oatley, 2008). Thus, we also hypothesized that people may report recalling memories of fiction for the social function more frequently than for a directive or self function. Finally, we sought to provide a replication of previous work establishing the degree to which people endorse these theoretically driven functions of autobiographical remembering.

\section{Methods}

\section{Participants}

We recruited 164 participants $\left(M_{\mathrm{age}}=33.8, S D_{\text {age }}=10.8,74\right.$ women, 1 undeclared gender) from the United States completed the study through Amazon's Mechanical Turk (MTurk) in return for monetary compensation. In this study, $46.6 \%$ of participants reported at least a bachelor's degree and $89.6 \%$ reported taking at least some college courses. Our initial estimate of sample size was guided by previous work with the TALE (Bluck et al., 2005). No participants were excluded from analysis. Participants were randomly assigned to retrieve and rate a personal or fictional memory. These procedures were approved by the Duke Institutional Review Board, and all participants gave informed consent before beginning the studies.। 


\section{Materials}

We used the TALE questionnaire to probe personal memories (Bluck et al., 2005), and administered a close adaptation of the TALE to address memories of fiction. Error! Reference source not found. shows a representative sample of items; materials are available online at osf.io/m2aew.

The first two questions of the TALE for both conditions (personal and fictional) probe the overall frequency of talking and thinking about memories: "How often do you think back over (your life) / (works of fiction)?" and "How often do you talk to others about (what's happened) / (works of fiction you have consumed) in your life so far?" Twenty-eight items followed to assess directive, self, and social functions of remembering. Each item was rated on a scale of 1 ("never") to 6 ("very frequently"), with descriptive anchors for each point. Per previous work, these 28 items were displayed in a fixed random order for both conditions.

\section{Table S3.}

\section{Sample TALE items in Pilot}

Personal Condition

I think back over or talk about my life or certain periods of my life...

Directive ...when I feel I can learn a lesson about something bad that happened by thinking about it.

Self $\quad$...when something unexpected happens to me and I want to fit it into my view of my life.

Social $\quad$...when I want to make myself feel better by talking to others who have had similar past experiences.

\section{Fiction Condition}

I think back over or talk about events from fictional works...

...when I feel I can learn a lesson about something bad that happened in the story.

...when something unexpected happens to me and I want to fit it into my view of my life.

...when I want to make myself feel better by thinking about events in stories similar to my current experience.

Note. 1 to 6 scale: $1=$ Never, $2=$ Rarely, $3=$ Seldom, $4=$ Occasionally, $5=$ Often, and $6=$ Very Frequently. 


\section{Procedure}

Participants completed either the personal or fictional version of the TALE questionnaire, due to concerns that how participants answered questions on one version of the survey would influence responses on the other version. The survey was self-paced, and up to five questions appeared on the screen at the same time. After completing the survey, participants reported demographic information such as gender, age, level of education, and first language. After completing the survey, participants were thanked and compensated.

\section{Results}

First, we examined the two items probing the general frequency of thinking and talking about personal memories or memories of fiction. Participants reported thinking about personal memories slightly more than memories of fiction $\left(M_{\text {personal }}=4.54, M_{\text {fiction }}=4.23, S D_{\text {personal }}=\right.$ $\left.0.86, S D_{\text {fiction }}=1.03, t(162)=2.08, p=.04, d=0.32[0.01,0.64]\right)$, although the median was 4 (occasionally) for both conditions. Participants reported talking about memories of fiction more frequently than personal memories $\left(M_{\text {personal }}=3.80, M_{\text {fiction }}=4.57, S D_{\text {personal }}=0.93, S D_{\text {fiction }}=\right.$ $1.40, t(138.72)=4.14, p<.0001, d=0.65[0.33,0.96])$.

Next, we examined the specific reasons why people reported thinking or talking about their life or works of fiction, divided into directive, self, and social functions. Thus, these 28 items were averaged into their respective three subscales, which proved at least as reliable as previously reported work, with comparable measures of Cronbach's $\alpha$ (all $\alpha>.85)$. 
Figure S1 shows how frequently participants reported using personal memories or memories of fiction for directive, self, and social functions.

\section{Figure S1.}

\section{Bar Graph of Personal and Fictional Means and SEMs for Directive, Self, and Social} Subscales in Study 3
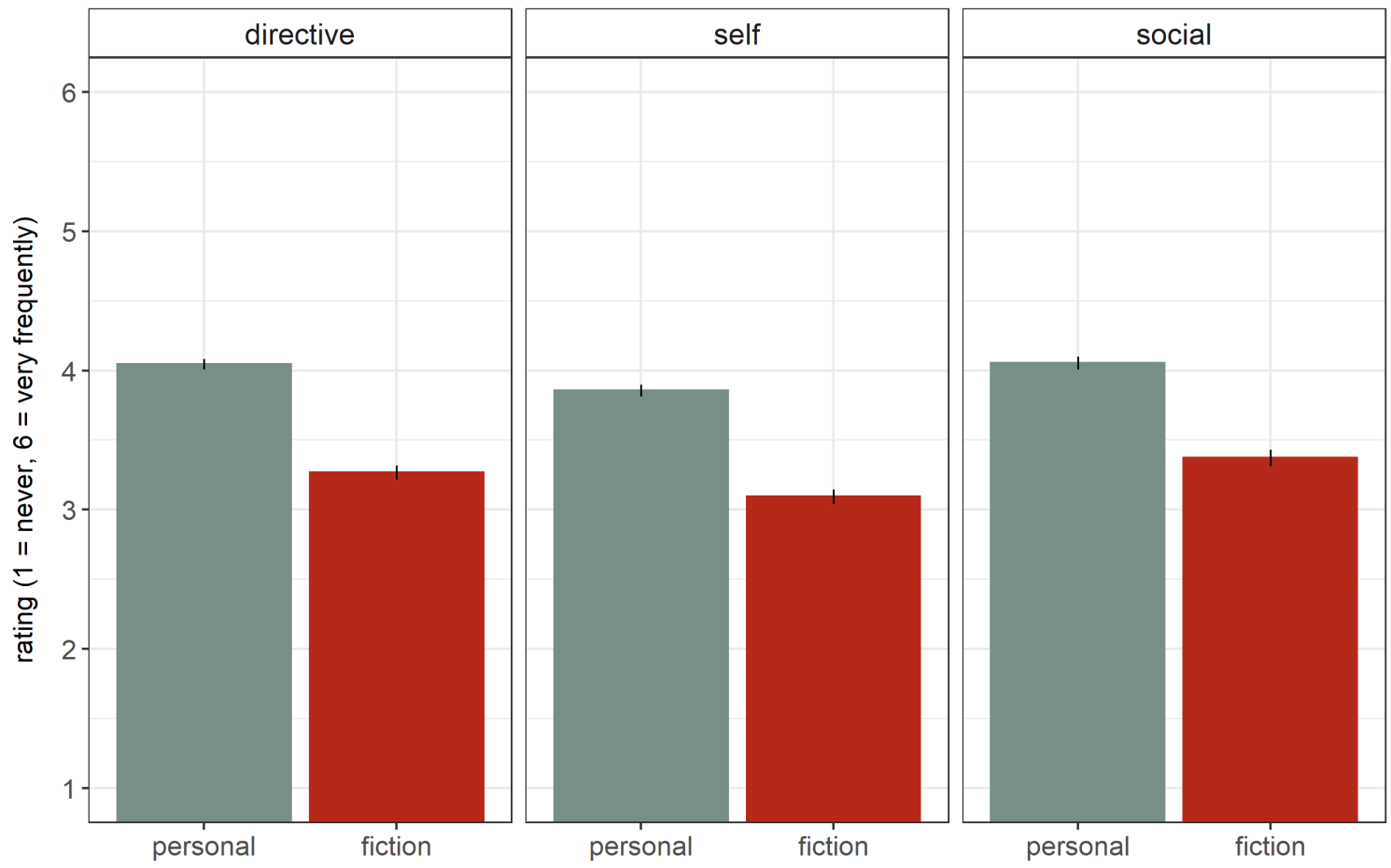

Reported usage of personal memories was very similar to that reported in Bluck et al. (2005), replicating this previous study. Participants consistently reported using their personal memories more frequently than memories of fiction for all three functions (Cohen's $d$ ranging from 0.51 to 0.60 ). This difference between conditions was also consistent across individual items: personal memories were rated higher on average than memories of fiction for all 28 items except one: "I think back over or talk (about my life or certain periods of my life) / (events from fictional works) when I feel down and I want to make myself feel better." 
Of interest is an apparent discrepancy: participants report talking about fiction more than their personal pasts when probed generally, but not when asked using the more specific items that make up the social subscale. While this could be due to inconsistencies in participants' selfreport strategies, it hints that people may in fact think or discuss memories of fiction more often than is represented on these subscale items, especially in social contexts. For the social subscale, we note that the median was 4 for both fictional and personal conditions. The items on the TALE were developed and validated with respect to personal memories; they were not designed with the intent of including memories of fiction. Our present data offer evidence for overlapping functions between memories of lived experience and of fiction. However, to the extent that fiction may offer unique functions - ones distinct from personal memories - the present measures do not yet capture them.

This study documents that people report talking and thinking about memories of events from works of fiction on a regular basis, albeit at a lower rate than personal memories. People report drawing on memories of fictional events — which by definition, never happened— to solve problems in their lives, maintain a sense of self, and to create and maintain social relationships. 


\section{Study 1 Supplemental Results}

Table S4.

Means, Standard Deviations, and Mean Comparisons Between Personal and Fictional

Conditions for AMQ Items in Study 1

\begin{tabular}{lccccc}
\hline \multicolumn{1}{c}{ Item } & $\begin{array}{c}\text { Personal } \\
\text { Mean (SD) }\end{array}$ & $\begin{array}{c}\text { Fictional } \\
\text { Mean (SD) }\end{array}$ & $t(104)$ & $\begin{array}{c}\text { Uncorrected } \\
p \text {-value }\end{array}$ & $\begin{array}{c}\text { Cohen's } d \\
{[95 \% \mathrm{CI}]}\end{array}$ \\
\hline Rehearsal & $4.91(1.51)$ & $4.42(1.41)$ & $2.79 \dagger$ & .006 & $0.27[0.00,0.55]$ \\
Visual imagery & $5.79(1.25)$ & $5.64(1.12)$ & 1.15 & .255 & $0.11[-0.16,0.39]$ \\
Auditory imagery & $5.32(1.63)$ & $5.19(1.36)$ & 0.69 & .49 & $0.07[-0.21,0.34]$ \\
Reliving & $5.11(1.65)$ & $3.50(1.85)$ & $8.55^{* * * *}$ & $<.0001$ & $0.83[0.55,1.12]$ \\
Same strength of & $5.23(1.63)$ & $4.88(1.52)$ & 2.24 & .03 & $0.22[-.06,0.49]$ \\
emotions & & & & & .008 \\
Intensity of emotions & $4.99(1.57)$ & $4.46(1.53)$ & $2.70 \dagger$ & $0.26[-.01,0.54]$ \\
Valence: positivity & $4.63(2.24)$ & $4.41(1.95)$ & 0.80 & .43 & $0.08[-0.20,0.35]$ \\
Valence: negativity & $3.06(2.20)$ & $3.08(2.06)$ & 0.07 & .94 & $0.01[-0.27,0.28]$ \\
Accuracy & $5.70(1.51)$ & $5.87(1.22)$ & 1.23 & .22 & $0.12[-0.15,0.39]$ \\
\hline
\end{tabular}

Note. $\uparrow<.10, * p<.05, * * p<.01, * * * p<.001, * * * * p<.0001$ after Bonferroni correction for multiple comparisons.

\section{Table S5.}

Means, Standard Deviations, and Mean Comparisons Between Personal and Fictional Conditions for Memory Role Items (CES and Function) in Study 1

\begin{tabular}{llllc}
\hline Item & Personal & Fictional & $\mathrm{t}(96)$ & $\begin{array}{l}\text { Cohen's d [95\% } \\
\text { CI] }\end{array}$ \\
\hline CES: Identity & $3.43(1.31)$ & $2.10(1.23)$ & $8.84 * * * *$ & $0.86[0.58,1.15]$ \\
CES: Reference point & $3.00(1.31)$ & $2.06(1.21)$ & $6.59 * * * *$ & $0.64[0.36,0.92]$ \\
CES: Life story & $3.14(1.43)$ & $1.72(1.05)$ & $9.50^{* * * * *}$ & $0.93[0.64,1.22]$ \\
CES: Colors other experiences & $3.22(1.32)$ & $2.22(1.27)$ & $6.98^{* * * *}$ & $0.68[0.40,0.96]$ \\
Directive & $2.71(1.29)$ & $1.73(1.08)$ & $5.77 * * * *$ & $0.83[0.53,1.13]$ \\
Self & $3.05(1.25)$ & $2.06(1.17)$ & $5.69 * * * *$ & $0.82[0.522,1.11]$ \\
Social & $2.95(1.36)$ & $1.93(1.17)$ & $5.57 * * * *$ & $0.80[0.51,1.10]$ \\
\hline
\end{tabular}

Note. $\dagger<.1, * \mathrm{p}<.05, * * \mathrm{p}<.01, * * * \mathrm{p}<.001, * * * * \mathrm{p}<.0001$ 


\section{Study 2 Supplemental Results}

Table S6.

Means, Standard Deviations, and Mean Comparisons Between Personal and Fictional

Conditions for AMQ Items in Study 2

\begin{tabular}{|c|c|c|c|c|}
\hline \multicolumn{5}{|l|}{ AMQ (scale 1 to 7) } \\
\hline Item & $\begin{array}{c}\text { Personal } \\
\text { Mean (SD) }\end{array}$ & $\begin{array}{l}\text { Fictional Mean } \\
\text { (SD) }\end{array}$ & $t$ & Cohen's $d[95 \% \mathrm{CI}]$ \\
\hline Rehearsal & $3.48(0.99)$ & $2.81(0.93)$ & $3.57 * *$ & $0.70[0.30,1.10]$ \\
\hline Visual imagery & $5.23(1.01)$ & $4.58(0.84)$ & $3.59 * *$ & $0.70[0.30,1.11]$ \\
\hline Auditory imagery & $4.30(1.37)$ & $3.91(1.12)$ & 1.59 & $0.31[-.08,0.70]$ \\
\hline spatialLayout & $5.33(1.07)$ & $4.37(1.05)$ & $4.63 * * *$ & $0.91[0.50,1.32]$ \\
\hline Reliving & $4.75(1.19)$ & $3.68(1.18)$ & $4.60 * * *$ & $0.90[0.49,1.31]$ \\
\hline Same strength of emotion & $4.23(1.24)$ & $3.46(1.15)$ & $3.33^{*}$ & $0.65[0.25,1.05]$ \\
\hline sameFeelings & $4.50(1.26)$ & $3.53(1.14)$ & $4.12 * * *$ & $0.81[0.40,1.21]$ \\
\hline Positivity of emotions & $4.34(1.00)$ & $3.90(1.06)$ & 2.16 & $0.42[0.03,0.82]$ \\
\hline Negativity of emotions & $2.99(0.98)$ & $2.89(1.08)$ & 0.51 & $0.10[-.29,0.49]$ \\
\hline Intensity of emotions & $3.91(1.09)$ & $3.20(1.22)$ & $3.12 *$ & $0.61[0.21,1.01]$ \\
\hline Accuracy & $5.33(1.07)$ & $4.82(1.10)$ & 2.38 & $0.47[0.07,0.86]$ \\
\hline beliefRealImagine & $5.50(0.94)$ & $4.75(0.99)$ & $3.93 * *$ & $0.47[0.37,1.17]$ \\
\hline beliefTestify & $5.13(1.26)$ & $3.97(1.34)$ & $4.56^{* * *}$ & $0.77[0.49,1.30]$ \\
\hline \multicolumn{5}{|c|}{$\begin{array}{l}\text { Note. } \dagger<.1, * p<.05, * * p<.01, * * * p<.001 \text { after Bonferroni correction. Standard deviations are } \\
\text { shown in parentheses. These analyses were conducted by averaging personal memories and } \\
\text { memories of fiction for each participant. A multilevel model, taking in account each observation and } \\
\text { modeling participant as a second level, yields the same conclusions; thus, averages are reported here } \\
\text { for clarity. }\end{array}$} \\
\hline
\end{tabular}




\section{Visual Perspective}

Replicating the results of Study 1, we found that personal memories tended to be remembered with a field perspective, and memories of fiction with an observer perspective.

\section{Table S7.}

Visual Perspective Results for Study 2

\begin{tabular}{lcccc}
\hline Item & Personal Mean (SD) & $\begin{array}{l}\text { Fictional Mean } \\
(\mathrm{SD})\end{array}$ & $t$ & Cohen's $d[95 \% \mathrm{CI}]$ \\
\hline Field & $5.57(1.61)$ & $3.19(2.14)$ & $9.89^{* * *}$ & $1.17[0.74,1.59]$ \\
Observer & $3.77(2.08)$ & $5.07(1.83)$ & $4.86^{* * *}$ & $0.73[0.32,1.13]$ \\
Switch & $3.19(1.49)$ & $2.61(1.44)$ & $4.27^{*}$ & $0.33[0.06,0.72]$ \\
\hline
\end{tabular}

Note. $\dagger<.1,{ }^{*} \mathrm{p}<.05,{ }^{* *} \mathrm{p}<.01, * * * \mathrm{p}<.001$. This was a 7 -point scale.

In Study 2, we also altered the items used to measure visual perspective. Study 1 asked participants to categorize each memory as field, observer, mixed, or neither perspective. Study 2 assessed visual perspective with a different approach, as the previous approach puts the two perspectives in false opposition to each other, as events can be experienced as a combination of both perspectives (Rice \& Rubin, 2009). Thus, two items probed the extent to which people experienced the memory from a field and observer perspective $(1=$ not at all, $7=\mathrm{I}$ know exactly where I am seeing the event from) and one item probed participants' abilities to switch between perspectives ( $1=\mathrm{I}$ cannot switch perspectives, $5=\mathrm{I}$ can switch perspectives easily), in keeping with previous work in this area. 


\section{SI Table 8.}

Means, Standard Deviations, and Mean Comparisons Between Personal and Fictional

Conditions for CES and TALE Items in Study 2

\begin{tabular}{|c|c|c|c|c|}
\hline \multicolumn{5}{|c|}{ Centrality of Events Scale (scale from 1 to 5) } \\
\hline Item & $\begin{array}{l}\text { Personal Mean } \\
\quad(\mathrm{SD})\end{array}$ & $\begin{array}{l}\text { Fictional Mean } \\
\quad \text { (SD) }\end{array}$ & $t$ & Cohen's d $[95 \% \mathrm{CI}]$ \\
\hline Identity & $1.87(0.75)$ & $1.30(0.45)$ & $4.70 * * *$ & $0.92[0.51,1.33]$ \\
\hline Reference point & $1.88(0.78)$ & $1.41(0.52)$ & $3.59 * *$ & $0.70[0.30,1.10]$ \\
\hline Life story & $1.75(0.69)$ & $1.24(0.49)$ & $4.32 * * *$ & $0.85[0.44,1.25]$ \\
\hline Colors other experiences & $2.15(0.83)$ & $1.51(0.59)$ & $4.53 * * *$ & $0.89[0.48,1.30]$ \\
\hline \multicolumn{5}{|l|}{ Function (scale from 1 to 5 ) } \\
\hline Item & Personal & Fictional & Welch's $t$ & Cohen's d [95\% CI] \\
\hline Directive & $1.81(1.07)$ & $1.37(0.82)$ & $5.08 * * * *$ & $0.46[0.28,0.64]$ \\
\hline Self & $2.06(1.22)$ & $1.35(0.77)$ & $7.69 * * * *$ & $0.70[0.51,0.88]$ \\
\hline Social & $2.37(1.31)$ & $1.46(0.90)$ & $9.02 * * * *$ & $0.82[0.63,1.00]$ \\
\hline \multicolumn{5}{|c|}{$\begin{array}{l}\text { Note. } \dagger<.1, * p<.05, * * p<.01, * * * p<.001, * * * * p<.0001 \text { with Bonferroni corrections per group of } \\
\text { measures. }\end{array}$} \\
\hline \multicolumn{5}{|c|}{$\begin{array}{l}\dagger<.0077, * p<.0038, * * p<.0008, * * * p<.00008 \\
\dagger<.025, * p<.013, * * p<.0025, * * * p<.00025 \\
\dagger<.017, * p<.0083, * * p<.0017, * * * p<.00017\end{array}$} \\
\hline
\end{tabular}




\section{Study 3 Supplemental Results}

Figure S2.

Temporal Distribution for Study 3

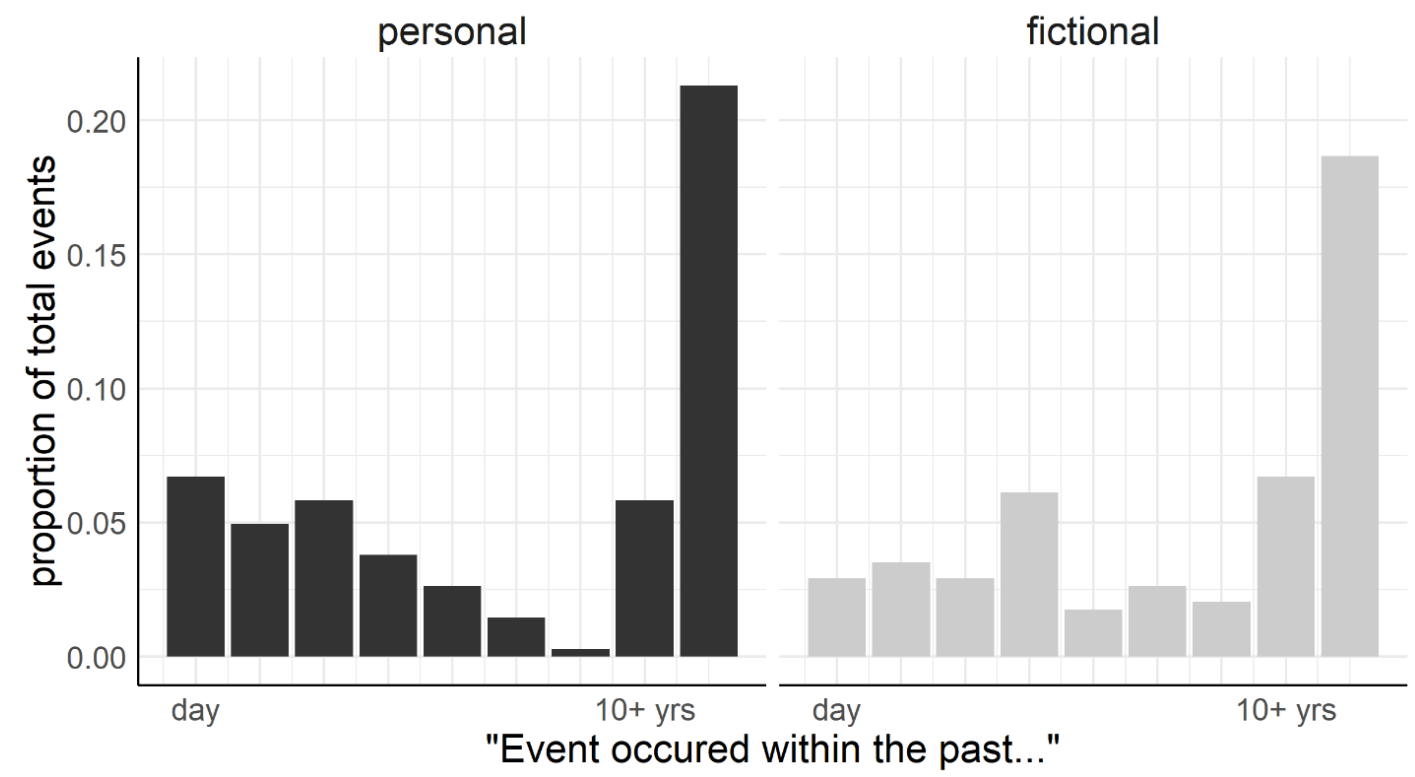

Table S9.

Descriptive Statistics for Function Items in Study 3

\begin{tabular}{rcccc}
\hline & $\begin{array}{c}\text { Directive Mean } \\
(\text { SD })\end{array}$ & $\begin{array}{c}\text { Self Mean } \\
(\text { SD) }\end{array}$ & $\begin{array}{c}\text { "Social” Mean } \\
(\text { SD })\end{array}$ & $\begin{array}{c}\text { Belong Mean } \\
\text { (SD) }\end{array}$ \\
\hline $\begin{array}{r}\text { Personal } \\
\text { Recent }\end{array}$ & $3.05(2.02)$ & $3.55(2.00)$ & $3.61(2.13)$ & $3.53(2.16)$ \\
$\quad \begin{array}{l}\text { Childhood } \\
\text { Fiction }\end{array}$ & $2.44(1.73)$ & $3.25(1.91)$ & $3.25(1.87)$ & $2.81(1.93)$ \\
Recent & $2.00(1.73)$ & $2.32(1.86)$ & $2.89(1.81)$ & $2.09(1.53)$ \\
Childhood & $1.65(1.18)$ & $2.37(1.69)$ & $2.59(1.75)$ & $2.22(1.60)$ \\
\hline
\end{tabular}

Note. 7-point scale.

\section{Dimensionality Reduction: Factor Analysis Details}

Based on previous literature and analyses, we hypothesized factors for belief (e.g., belief in the accuracy of event and willingness to testify about the events in a court of law), 
emotionality (e.g., strength of emotions, positivity of memory), recollection (e.g., sense of reliving, visual imagery), frequency of retrieval (e.g., frequency the event is thought or talked about), visual perspective (e.g., field and/or observer perspective), and impact/significance (TALE and CES items). We predicted the items would fall under the following factors:

\section{Table S10.}

\section{Hypothesized Factor Structure in Study 3}

\begin{tabular}{llllll}
\hline Belief & Emotionality & Recollection & Retrieval & $\begin{array}{l}\text { Visual } \\
\text { Perspective }\end{array}$ & Impact \\
\hline Belief 1 & Emotions & See & Thought & Field & 4 Function \\
Belief 2 & Intense & Hear & Talked & Observer & items \\
Accurate & Positive & Layout & Voluntary & Switch & 4 CES items \\
& Negative & Reliving & Involuntary & & \\
& & Same Feelings & & & \\
& & &
\end{tabular}

\section{Exploratory Factor Analysis}

To explore the factorial structure of personal and fictional event memories, all 27 items of the AMQ, TALE, and CES were used to compute a maximum likelihood factor analysis with oblique rotation (oblimin). Measures of retrieval, recollection, visual perspective, and significance are theoretically correlated and were found to be so in our previous studies; thus, we allowed the factors to correlate with each other with an oblique rotation. The Kaiser-Meyer Olkin measure verified the sampling adequacy for the analysis, $\mathrm{KMO}=.90$. Bartlett's test of sphericity $\chi^{2}(351)=1757.4, p<.0001$, indicated the correlation structure is adequate for factor analyses. We hypothesized a 6-factor solution, which was confirmed with parallel analysis as implemented in the `psych` package in RStudio.

Interestingly, all four factors identified in previous research computing a factor analysis of the AMQ — recollection, belief, impact, rehearsal—were in the present analysis (Fitzgerald \& Broadbridge, 2013). 
The first factor identified relates to the dimension of significance and includes all four of the CES items as well as three of the four autobiographical memory function items (directive, self, belong) and is similar to the dimension of impact in previous research.

The second factor identified relates to the tendency for the memory for be retrieved or rehearsed (retrieval) and includes measures relating to how often the event is thought about and talked about, the social function item, and how often the memory was retrieved voluntarily or involuntarily. We note that the social function item as implemented in this study, in retrospect, more closely relates to the estimated frequency of recounting than the degree to which a memory affects social interactions and relationships: "I have often shared this memory with other people." Thus, our analyses are unable to speak to the potential social functions of personal memories.

The third factor relates to recollection of the event and included six measures: strength of emotions, same feelings or atmosphere again, sense of reliving, auditory imagery, visual imagery, and intensity of emotions.

The fourth factor relates to belief, and included items relating to confidence in the accuracy of the memory and willingness to testify about the events in play.

The fifth factor related to the valence of the memory, and included the items of positivity and negativity, which were negatively related to each other.

The sixth factor related to visual perspective of the memory and included the items of field and observer visual perspectives. The items relating to spatial layout and ability to switch perspectives did have loadings greater than .40 .

Overall, the factor analysis confirmed what we hypothesized. The "strength of emotions" item ("When remembering the event, I feel the emotions as strongly as when I originally 
experienced it.") and intensity of emotions item (“The emotions I feel are intense”) actually loaded onto recollection, rather than the hypothesized "emotions", most strongly. When we examined the items, we found that the loading from the EFA is perhaps a better fit than the one initially hypothesized, as these items as more about the strength or vivacity of recollecting the event memory. On the other hand, the other items about emotion ("When remembering the event, the emotions are extremely positive/negative") are more to do with the valence of the memory. The factor analysis also put function: social item with the retrieval factor, rather than the other function items. This is also logical, as the item is: "I have often shared this memory with other people", so that makes sense.

\section{Confirmatory Factor Analysis}

The model that emerged in the exploratory factor analysis described above was further examined using confirmatory factor analysis. The model that included the perspective factor did not converge, so this factor was removed; results involving visual perspective is examined further below. Thus, maximum likelihood extraction was used to estimate the model with the five remaining factors. We ran two models: one with and one without the 'intense' variable in the recollection factor, due to its irregular behavior. We found that the model without the intense variable performed slightly better on multiple fit measures, and to reduce unnecessary complexity, removed it from the model. Including the 'intense` variable does not alter conclusions drawn from this model and subsequent results. The final model showed an acceptable fit: $\mathrm{CFI}=.92, \mathrm{TLI}=.91, \mathrm{RMSEA}=.08, \mathrm{SRMR}=.07, \mathrm{AIC}=23,564.14, \mathrm{BIC}=$ $23,753.39, \chi^{2}(183)=650.56, p<.001$ (Schreiber et al., 2006). Given the convergence of past literature with our hypothesized factors and results of the exploratory and confirmatory factor analyses, we felt confidence using these six factors to guide our results for Study 3. However, we 
note that this study was designed to analyze the latent structure of the variables at hand, and that the results of the factor analysis should be taken as exploratory.

Table S11.

Exploratory Factor Analysis: Standardized Loadings (Pattern Matrix) in Study 3

\begin{tabular}{|c|c|c|c|c|c|c|c|}
\hline \multirow{3}{*}{ Items } & \multicolumn{6}{|c|}{ Factor } & \multirow{3}{*}{ Dimension } \\
\hline & & & & & & & \\
\hline & $\begin{array}{c}1 \\
\text { ML3 }\end{array}$ & $\begin{array}{c}2 \\
\text { ML5 }\end{array}$ & $\begin{array}{c}3 \\
\text { ML6 }\end{array}$ & $\begin{array}{c}4 \\
\text { ML4 }\end{array}$ & $\begin{array}{c}5 \\
\text { ML1 }\end{array}$ & $\begin{array}{c}6 \\
\text { ML2 }\end{array}$ & \\
\hline CES1 & .88 & .01 & -.01 & .05 & -.06 & .00 & impact \\
\hline CES2 & .92 & -.04 & -0.01 & .00 & .04 & .80 & \\
\hline CES3 & .83 & .05 & -.01 & .01 & .02 & .04 & \\
\hline CES4 & .86 & -.04 & .08 & -.05 & .06 & .03 & \\
\hline function: directive & .69 & .14 & -.07 & .00 & .04 & -.03 & \\
\hline function: self & .81 & .04 & .05 & .02 & -.02 & -.07 & \\
\hline function: belong & .76 & .07 & .02 & .05 & -.16 & -.05 & \\
\hline talked & -.08 & .96 & -.03 & -.01 & .00 & -.01 & retrieval \\
\hline function: social & .15 & .79 & -.12 & .08 & -.03 & -.01 & \\
\hline voluntary retrieval & .05 & .75 & .09 & -.01 & .01 & .03 & \\
\hline thought & .02 & .70 & .17 & -.05 & .06 & .01 & \\
\hline involuntary retrieval & .21 & .49 & .17 & -.02 & .06 & .06 & \\
\hline strength of emotions & .11 & -.03 & .75 & .00 & -.01 & -.04 & recollection \\
\hline same feelings & .10 & .03 & .75 & .02 & -.06 & .01 & \\
\hline reliving & -.02 & .07 & .70 & .17 & .00 & -.05 & \\
\hline auditory imagery & -.10 & .09 & .60 & .21 & -.05 & .09 & \\
\hline visual imagery & -.09 & .06 & .56 & .26 & .06 & -.01 & \\
\hline intense & .18 & .14 & .54 & -.20 & .19 & .01 & \\
\hline accurate & .04 & -.03 & -.01 & .89 & .01 & .07 & belief \\
\hline belief: testify & .08 & -.01 & .05 & .84 & .00 & -.03 & \\
\hline belief: real/imagined & -.07 & .05 & .04 & .83 & .02 & -.05 & \\
\hline negative & .02 & .04 & .06 & .01 & .99 & .02 & valence \\
\hline positive & .07 & .06 & .18 & -.03 & -.76 & .06 & \\
\hline $\begin{array}{l}\text { perspective: } \\
\text { observer }\end{array}$ & .02 & .01 & .03 & .02 & .00 & 1.00 & $\begin{array}{l}\text { visual } \\
\text { perspective }\end{array}$ \\
\hline perspective: field & .123 & .12 & .03 & .25 & .11 & .04 & \\
\hline spatial layout & -.02 & .01 & .27 & .29 & .07 & -.05 & NA \\
\hline perspective: switch & .09 & -.13 & .23 & .01 & .03 & .24 & NA \\
\hline SS loadings & 4.95 & 2.94 & 2.92 & 2.48 & 1.66 & 1.41 & \\
\hline Proportion Var & .18 & .109 & .11 & .09 & .06 & .05 & \\
\hline Cumulative Var & .18 & .29 & .40 & .49 & .55 & .61 & \\
\hline
\end{tabular}

Notes. Extraction method: maximum likelihood. Rotation method: oblimin. Loadings larger than .40 are in bold. Layout and switch did not have factor loadings above .40 are not mapped onto a factor. 


\section{Figure S3.}

\section{Exploratory Factor Analysis Results in Study 3}

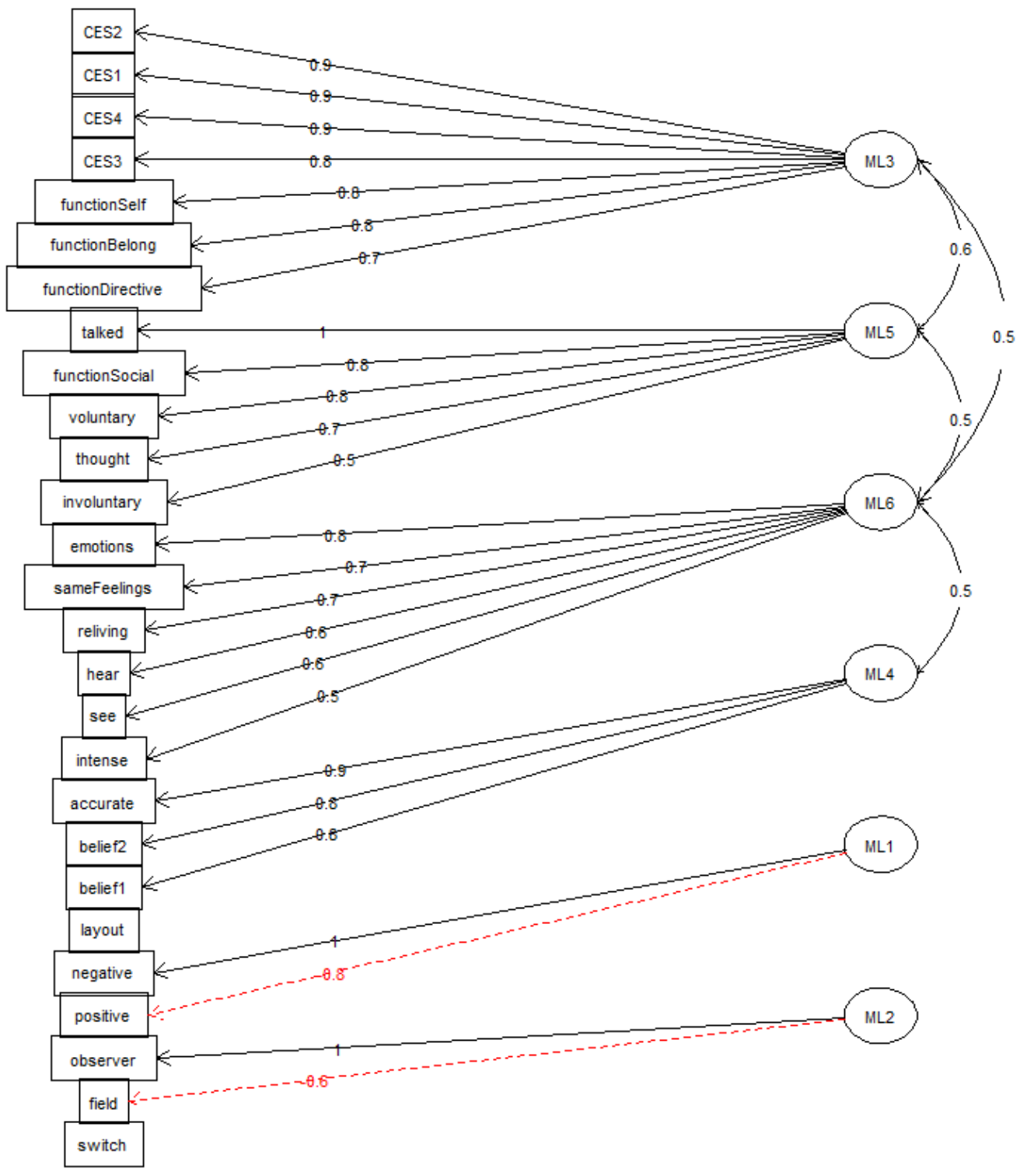


Table S12.

Within Factor Correlations in Study 3

\begin{tabular}{ccccccc}
\hline & 1 Impact & 2 Retrieval & 3 Recollection & 4 Belief & 5 Valence & 6 Perspective \\
\hline 1 & 1.00 & $\mathbf{0 . 6 0}$ & 0.13 & 0.13 & 0.05 & 0.01 \\
2 & $\mathbf{0 . 6 0}$ & 1.00 & $\mathbf{0 . 4 6}$ & 0.18 & 0.07 & 0.01 \\
3 & $\mathbf{0 . 4 5}$ & $\mathbf{0 . 4 6}$ & 1.00 & $\mathbf{0 . 5 3}$ & -0.02 & -0.02 \\
4 & 0.13 & 0.18 & $\mathbf{0 . 5 3}$ & 1.00 & -0.10 & -0.09 \\
5 & 0.05 & 0.07 & -0.02 & -0.10 & 1.00 & -0.06 \\
6 & 0.01 & 0.01 & -0.02 & -0.09 & -.06 & 1.00 \\
\hline
\end{tabular}

Note. Correlations larger than .40 are in bold. Layout and switch did not have factor loadings above .40 are not mapped onto a factor.

\section{Results}

\section{Figure S4.}

\section{Individual Item Means for the Belief Composite Variable}

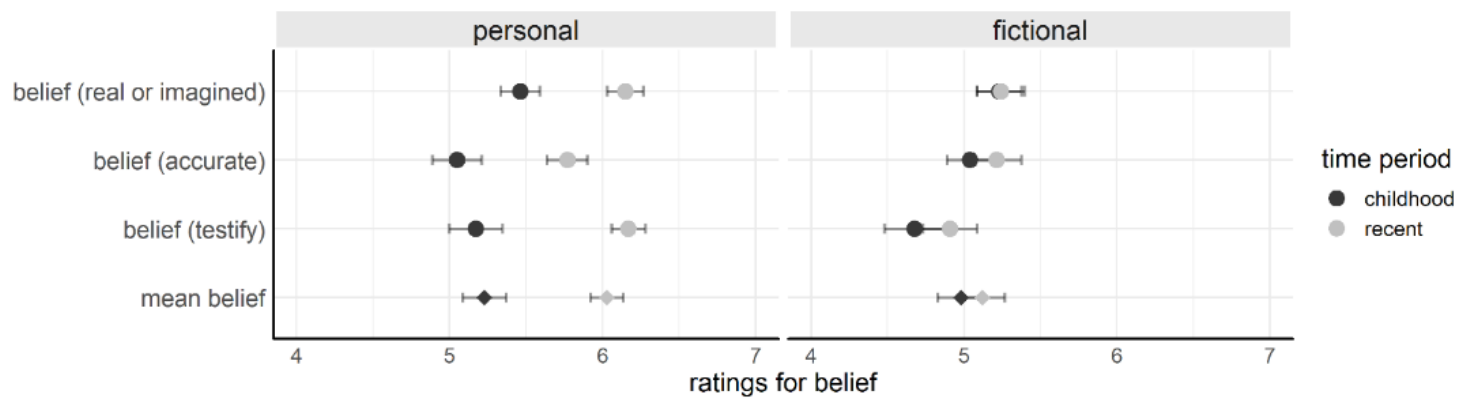

Note. Three items were averaged to create the retrieval composite. Means for the composite variable retrieval are shown as diamonds on the bottom row. 


\section{Figure S5.}

\section{Individual Item Means for the Retrieval Composite Variable}

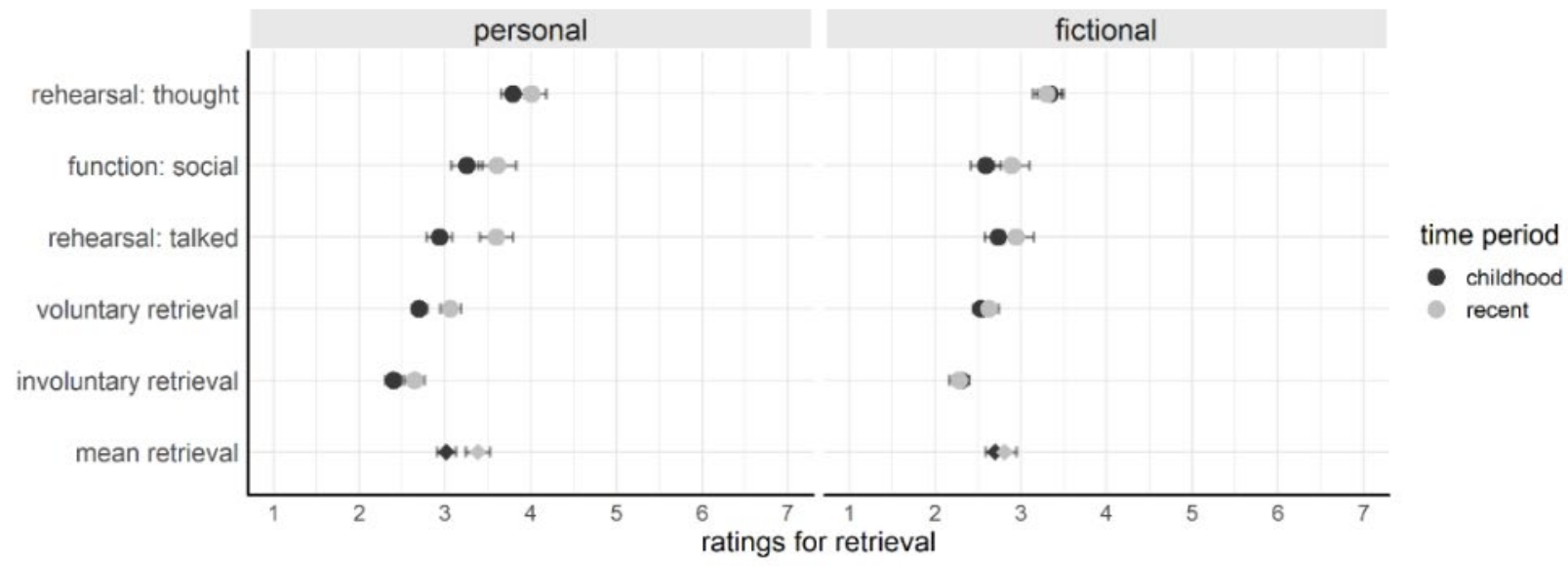

Note. Five items (rehearsal for both thought and talked about, voluntary and involuntary retrieval, and autobiographical social function) were averaged to create the retrieval composite. Means for the composite variable retrieval are shown as diamonds on the bottom row.

However, when we completed these analyses using a MANOVA framework - in other words, replacing the retrieval dependent measure with a multivariate combination of the five relevant variables - we found a statistically significant effect of the time condition (MATS = $15.40, p=0.04)$, in addition to the statistically significant effect of memory type yielded by the ANOVA above (MATS $=44.78, p=.002)$. Given this discrepancy, we explored this main effect in personal and fictional conditions by computing separate $t$-tests for both personal and fictional conditions. We found that personal childhood memories were retrieved slightly less often than were recent memories: $M_{\text {childhood }}=3.02, S D=1.15 ; M_{\text {recent }}=3.39, S D=1.38 ; t(199)=.044,95 \%$ CI of the difference $=[.01, .73]$, Cohen's $d=0.29$. In contrast, fictional memories from childhood and recent times were not statistically different on the factor of retrieval: $M_{\text {childhood }}=$ $2.70, S D=1.15 ; M_{\text {recent }}=2.81, S D=1.20 ; p=.53,95 \% \mathrm{CI}$ of the difference $=[-0.46,0.24]$. The 
overall pattern of results suggests that time has a larger effect for personal memories than for memories of fictional, similar to the pattern found for recollection.

This illustrates these results for each of the individual items that contributed to the retrieval composite variable and illustrates that the effect of time is inconsistent in some of the individual items in the personal condition. This likely explains the discrepancy found between the MANOVA and composite variable analysis frameworks.

\section{Figure S6.}

Individual Item Means for the Impact Composite Variable

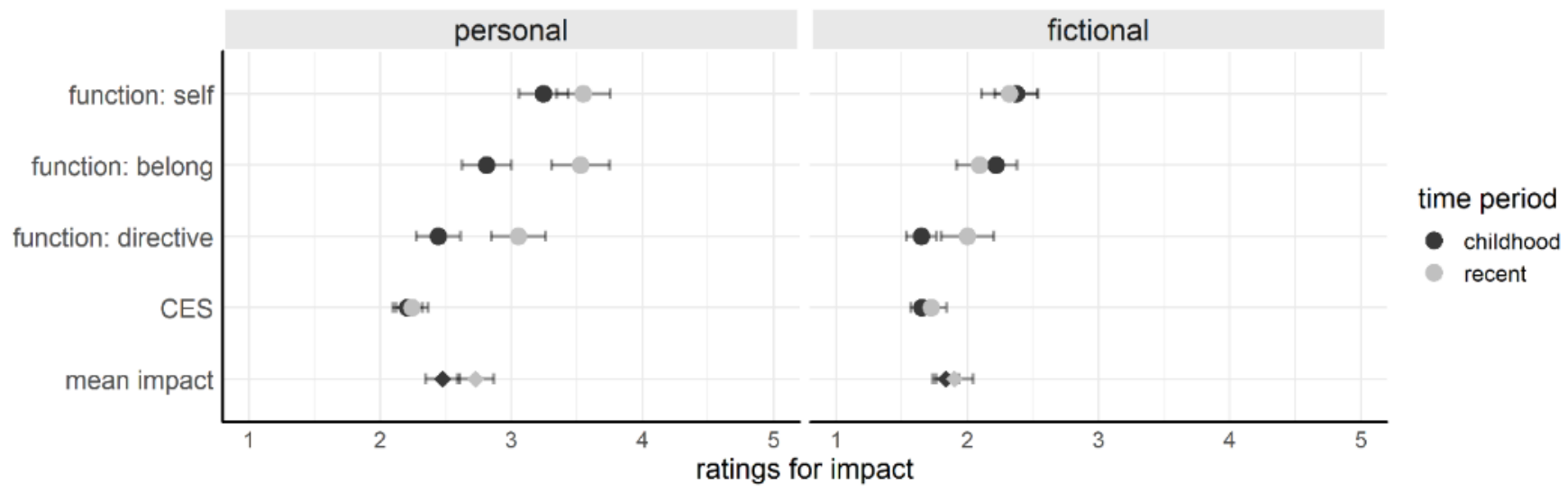

Note. Three function items (self, belong, directive) and four CES items were averaged to create the impact composite. The four CES items are collapsed in this figure for clarity. Means for the composite variable impact are shown as diamonds on the bottom row. 


\section{Figure S7.}

\section{Valence of Personal and Fictional Events by Time Period in Study 3}

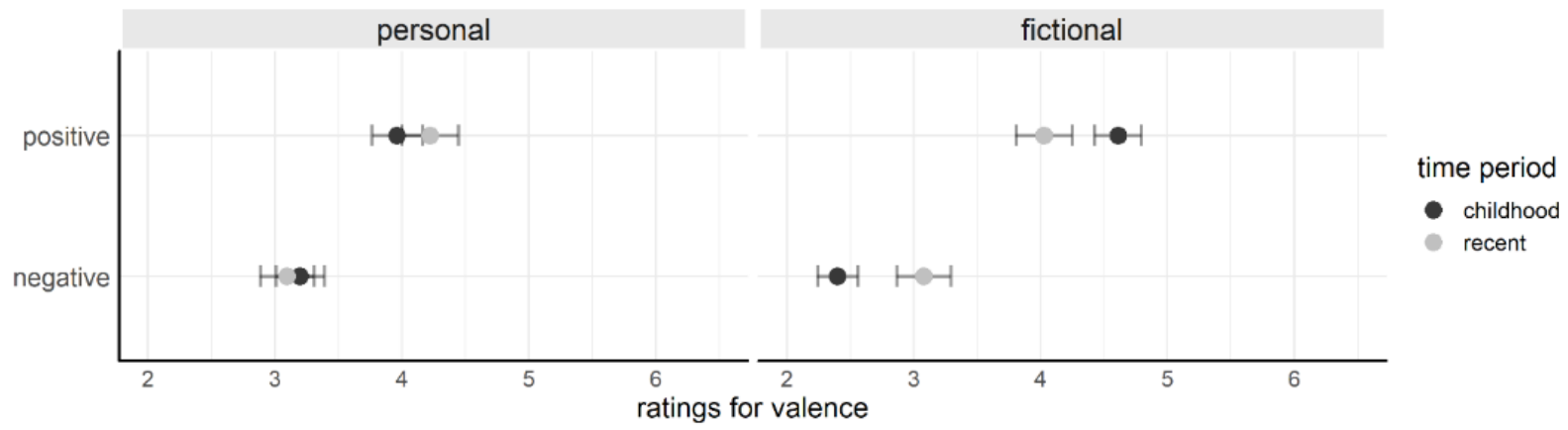

Visual Perspective Across Time

We investigated the role of perspective across time periods and memory types. We computed two-mixed effects ANOVAS with time (recent vs. childhood) as a between-subjects factor and memory type (personal vs. fictional) as a within-subjects factor on measures of field and observer perspective of the event memory. "Field" relates to a first-person perspective when reliving the event, whereas "observer" relates to a third-person perspective. For the model predicting field perspective, the ANOVA revealed a main effect of memory type $(F(1,211.47)=$ $154.22, p<.0001)$ and an interaction $(F(1,211.03)=8.69, p=.004)$. For the model predicting the observer perspective, the ANOVA also revealed a main effect of memory type $(F(1,201.48)$ $=92.97, p<.0001)$ and an interaction $(F(1,201.48)=5.34, p=.02)$. Overall, we replicated the finding from Studies 1 and 2 that personal memories are more likely to be recalled in a field perspective, and memories of fiction are more likely to be recalled from an observer perspective. Figure S8 illustrates these effects, which are in line with previous studies suggesting that personal memories are more likely to transform from field to observer-like with the passage of time (Nigro \& Neisser, 1983; Rice \& Rubin, 2009; Robinson \& Swanson, 1993). This is seen in Figure S8(A): recent personal events are rated highly for field perspective and low for the 
observer perspective. For recent childhood events, this gap narrows. However, for memories of fiction, this pattern is less evidence. Figure S8B shows this pattern more continuously, by plotting ratings for the field perspective against the number of years since the event was experienced; Figure S8C plots this for the observer perspective.

\section{Figure S8.}

Visual Perspective of Personal and Fictional Events by Time Period in Study 4

(A)

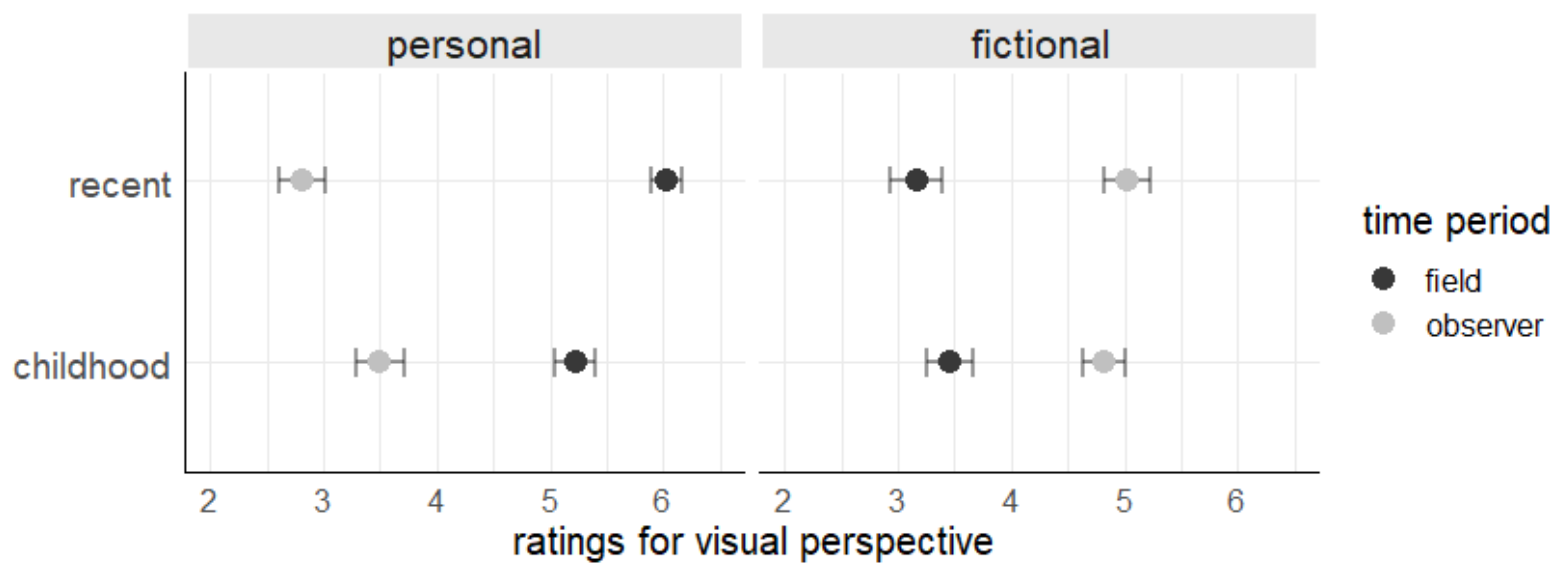

(B)

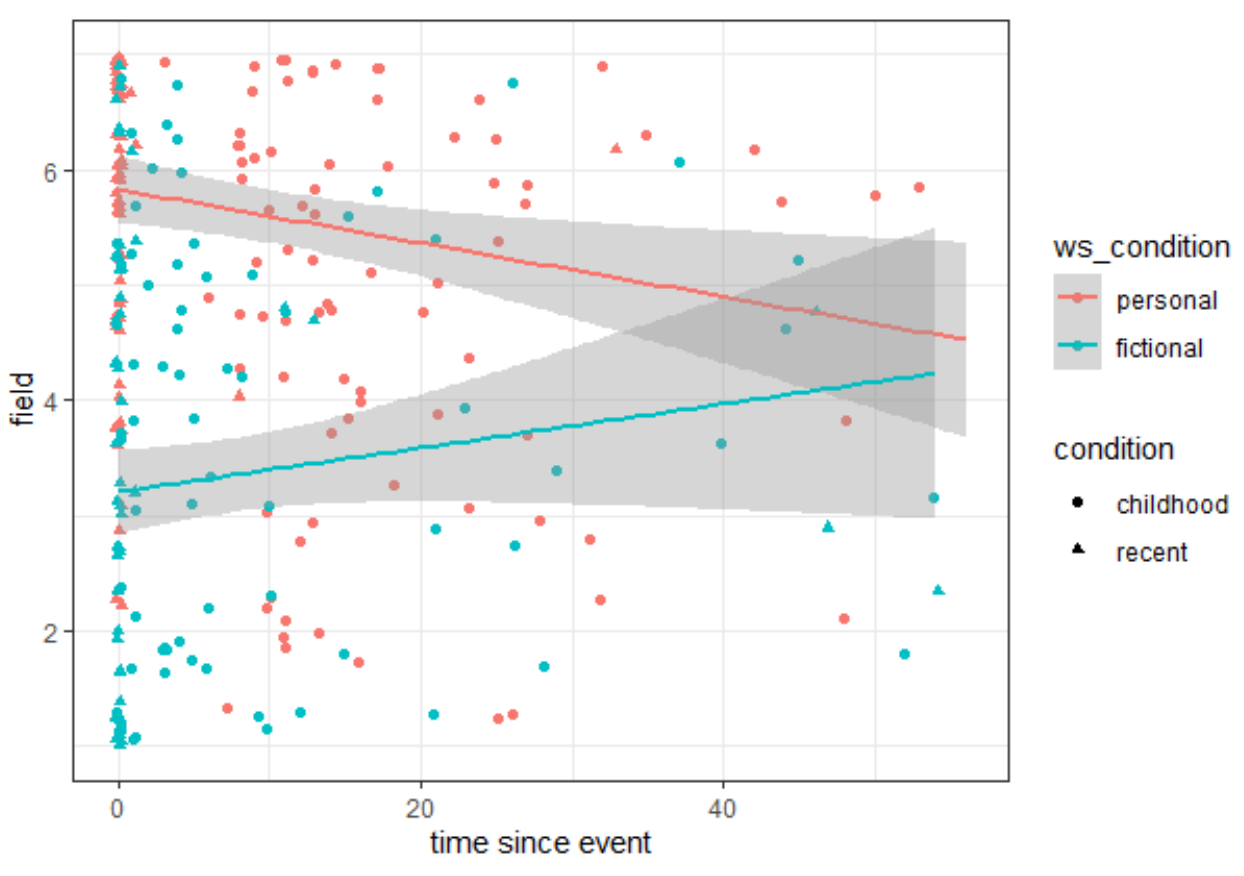




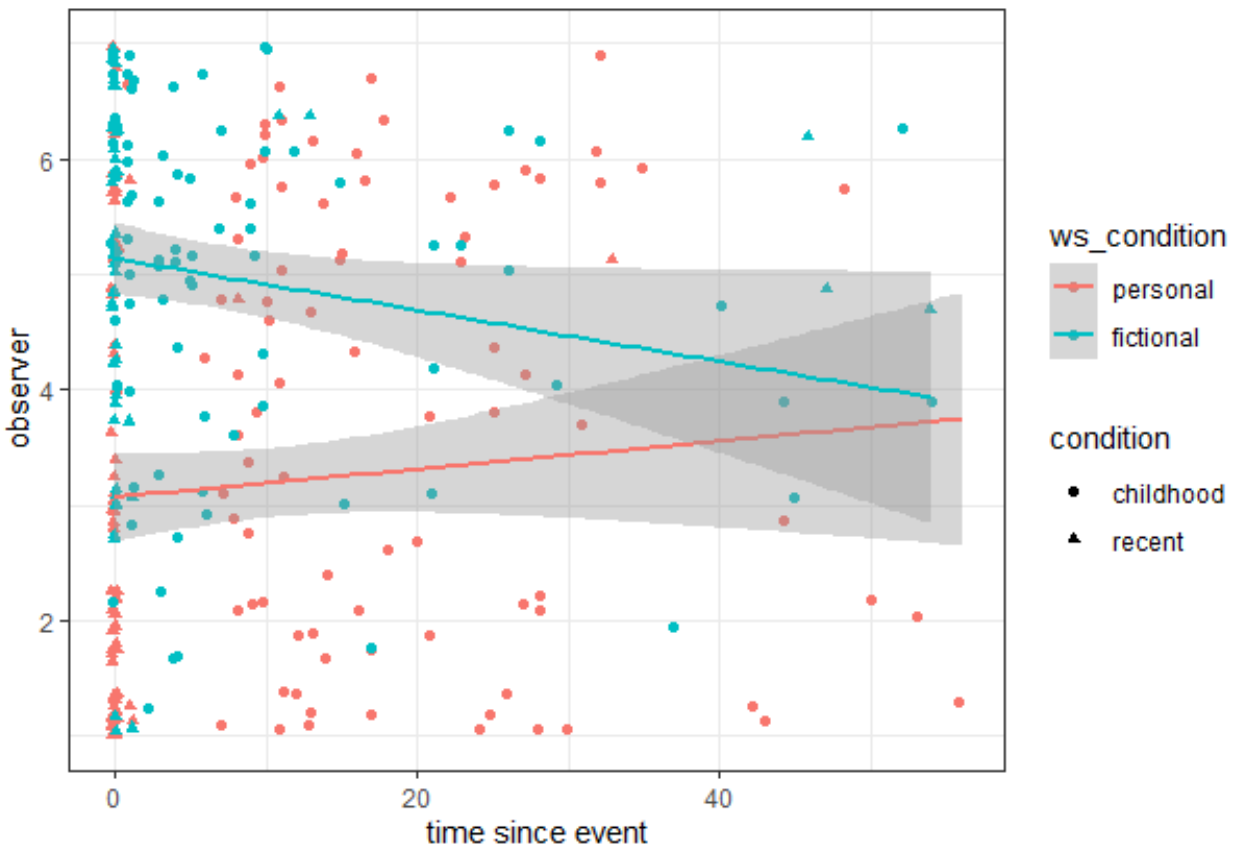

(C) 